\title{
Efforts Toward Developing Direct Probes of Protein Dynamics
}

\author{
Matthew E. Cremeens, ${ }^{\dagger}$ Hiroshi Fujisaki, ${ }^{\ddagger}$ Yong Zhang, ${ }^{\ddagger}$ Jörg Zimmermann, ${ }^{\dagger}$ Laura B. Sagle ${ }^{\dagger}$ \\ Shigeo Matsuda, ${ }^{\dagger}$ Philip E. Dawson, ${ }^{\dagger}$ John E. Straub, ${ }^{\dagger}$ and Floyd E. Romesberg ${ }^{\dagger *}$ \\ ${ }^{\dagger}$ Department of Chemistry, The Scripps Research Institute, 10550 North Torrey Pines Road, La Jolla, CA \\ 92037 and Department of Chemistry, Boston University, 590 Commonwealth Avenue, Boston, MA 02215
}

\section{Table of Contents.}

Experimental / G03 Computational Details: Additional Figures:

G03 Cartesian Coordinates:

$\mathrm{S} 1-\mathrm{S} 7$

S8

$\mathrm{S} 9-\mathrm{S} 10$

G03 Harmonic and Anharmonic Frequencies: S11 - S15

Resonant Modes / Numerical Analysis: $\quad$ S16 - S17

Materials. 2-(1H-Benzotriazol-1-yl)-1,1,3,3-tetramethyluronium hexafluorophosphate ${ }^{1}$ (HBTU) and $N^{\alpha}$-Boc-amino acids were obtained from Peptides International. L-4,4'Dithio-bis(2-aminobutanoic acid) was obtained from Bachem. $N, N$-Di-iso-propylethylamine $99.5 \% \quad$ (DIEA), and anisole $(99.7 \%)$ were obtained from Aldrich Chemical. Trifluoroacetic acid (TFA), horse heart cyt $c(90 \%), \mathrm{CNBr}$, and formic acid were obtained from Acros. HPLC grade $N, N$ dimethylformamide (DMF), HPLC grade acetonitrile, reagent grade methylene chloride, acetic anhydride, sodium acetate, and glacial acetic acid were obtained from Fisher Scientific. Boc-Glu(Ochx)-PAM resin was obtained from NeoMPS. HF was purchased from Matheson. Met- $d_{3}$ and $\mathrm{ICH}_{2} \mathrm{D}$ were obtained from Cambridge Isotopes.

HPLC. Analytical reversed-phase HPLC was performed on a Rainin Dynamax SD-200 solvent delivery system coupled to a Rainin Dynamax UV-D II absorbance detector with a $20 \mu \mathrm{L}$ sample loop (10 $\mu \mathrm{L}$ injections) using a Dynamax Microsorb C-18 column $(8 \mu \mathrm{m}, 0.46 \times 25 \mathrm{~cm}, 60 \AA$ pore size $)$. Preparative reversed-phase HPLC was performed with a $2 \mathrm{~mL}$ sample loop (900 $\mu \mathrm{L}$ injections) using a Dynamax C-4 column $(10 \mu \mathrm{m}, 2.14 \times 25 \mathrm{~cm}, 300 \AA$ pore size $)$. Linear gradients with acetonitrile in water, where all solutions contained $0.1 \%$ TFA by volume, were used to elute bound peptides. The flow rates were $0.8 \mathrm{~mL} / \mathrm{min}$ for analytical samples with a gradient of $1.5 \%$ per minute and $13 \mathrm{~mL} / \mathrm{min}$ for preparative samples with a gradient of $0.5 \%$ per minute. The detector was set to acquire data at $230 \mathrm{~nm}$. Samples were passed through a $0.22 \mu \mathrm{m}$ Millex-GV filter prior to injection.

Peptide/Protein MS. Electrospray ionization MS performed on an API-III triple quadropole mass spectrometer (Sciex, Thornhill, ON, Canada). Peptide masses were calculated from the experimental $\mathrm{m} / \mathrm{z}$ from all of the observed protonation states of a peptide by using MACSPEC software (Sciex). Theoretical masses of peptides and proteins were calculated by using MACPROMASS software (Beckman Research Institute, Duarte, CA).

Boc-Met- $d_{1}$ Synthesis. ${ }^{1} \mathrm{H}$ NMR in $\mathrm{CDCl}_{3}$ were referenced to tetramethylsilane, $\delta(\mathrm{ppm})=0$, and ${ }^{13} \mathrm{C} \mathrm{NMR}$ in $\mathrm{CDCl}_{3}$ were referenced to $\mathrm{CDCl}_{3}, \delta$ (ppm) $=77.000$.

Methyl ester of Boc-Met- $d_{1}$. The homocysteine dimer (L4,4'-dithio-bis(2-aminobutanoic acid)) was amine-protected with the tert-butoxycarbonyl (Boc) group, carboxyl-protected with a methyl ester, and the disulfide bond was cleaved following a literature protocol. ${ }^{2}$ The doubly protected

(1) The updated name is $N$-[(1H-benzotriazol-1-yl) dimethylamino)methylene]- $N$-methylmethanammonium hexafluorophophate $\mathrm{N}$-oxide. Abdelmoty, I.; Albericio, F.; Carpino, L. A.; Foxman, B. M.; Kates, S. A. Lett. Pept. Sci. 1994, 1, 57.

(2) Lherbet, C.; Keillor, J. W. Org. Biomol. Chem. 2004, 2, 238245. homocysteine was treated with $\mathrm{ICH}_{2} \mathrm{D}$ in $\mathrm{CH}_{2} \mathrm{Cl}_{2}$ and DIEA at room temperature and purified by flash column chromatography on silica gel. ${ }^{1} \mathrm{H} \mathrm{NMR}\left(\mathrm{CDCl}_{3}, 600 \mathrm{MHz}\right) \delta$ (ppm): N-H, 5.222 (d, 1H, J=6.6 Hz); $\mathrm{C}_{\alpha}-\mathrm{H}, 4.419$ (m, 1H); $\mathrm{CO}_{2} \mathrm{CH}_{3}, 3.754$ (s, 3H); $\mathrm{C}_{\gamma}-\mathrm{H}, 2.539$ (t, $\left.2 \mathrm{H}, J=7.5 \mathrm{~Hz}\right) ; \mathrm{C}_{\beta}-\mathrm{H}$, $2.125(\mathrm{~m}, 1 \mathrm{H}) ; \mathrm{SCH}_{2} \mathrm{D}, 2.084(\mathrm{t}, 2 \mathrm{H}, J=1.8 \mathrm{~Hz}) ; \mathrm{C}_{\beta}-\mathrm{H}, 1.934$ $(\mathrm{m}, 1 \mathrm{H}) ; \mathrm{C}\left(\mathrm{CH}_{3}\right)_{3}, 1.447(\mathrm{~s}, 9 \mathrm{H}) .{ }^{13} \mathrm{C} \mathrm{NMR}\left(\mathrm{CDCl}_{3}, 150\right.$ $\mathrm{MHz}) \delta(\mathrm{ppm}): \mathrm{CO}_{2} \mathrm{Me}, 172.682 ; \mathrm{OCONH}, 155.208 ; \mathbf{C M e}_{3}$, 79.822; $\mathrm{C}_{\alpha}, 52.609 ; \mathrm{CO}_{2} \mathrm{CH}_{3}, 52.251 ; \mathrm{C}_{\beta}, 32.025 ; \mathrm{C}_{\gamma}, 29.802$; $\mathrm{C}\left(\mathrm{CH}_{3}\right)_{3}, 28.169 ; \mathrm{SCH}_{2} \mathrm{D}, 15.079$ (t, $J=21.075 \mathrm{~Hz}$ ). High resolution ESI-TOF-MS $\left(\mathrm{C}_{11} \mathrm{H}_{20} \mathrm{O}_{4} \mathrm{NSD}, \mathrm{MNa}^{+}\right.$calc 287.1145 , $\mathrm{MNa}^{+}{ }_{\text {obs }}$ 287.1147).

Boc-Met- $d_{1}$. The methyl ester was removed with $\mathrm{NaOH}$ $(0.4 \mathrm{M})$ in $\mathrm{MeOH}: \mathrm{H}_{2} \mathrm{O}(4: 1)$ at room temperature and purified by flash column chromatography on silica gel to give BocMet- $d_{1} \cdot{ }^{1} \mathrm{H}$ NMR $\left(\mathrm{CDCl}_{3}, 600 \mathrm{MHz}\right) \delta(\mathrm{ppm})$ : N-H, 6.827 (d, $J=6.6 \mathrm{~Hz})$ and $5.364(\mathrm{~d}, J=6.6 \mathrm{~Hz}) ; \mathrm{C}_{\alpha}-\mathrm{H}, 4.454(\mathrm{~m})$ and $4.419(\mathrm{~m}) ; \mathrm{C}_{\gamma}-\mathrm{H}, 2.577$ (t, 2H, J=6.9 Hz); $\mathrm{C}_{\beta}-\mathrm{H}, 2.181$ (m, $1 \mathrm{H}) ; \mathrm{SCH}_{2} \mathrm{D}, 2.095(\mathrm{~s}, 2 \mathrm{H}) ; \mathrm{C}_{\beta}-\mathrm{H}, 1.990(\mathrm{~m}, 1 \mathrm{H}) ; \mathrm{C}\left(\mathrm{CH}_{3}\right)_{3}$, $1.451(\mathrm{~s}, 9 \mathrm{H})$ - has a downfield shoulder. ${ }^{13} \mathrm{C} \mathrm{NMR}\left(\mathrm{CDCl}_{3}\right.$, $150 \mathrm{MHz}) \delta$ (ppm): $\mathbf{C O}_{2} \mathrm{H}, 176.360$ and 176.007; $\mathrm{OCONH}$, 156.976 and $155.496 ; \mathrm{CMe}_{3}, 81.933$ and $80.151 ; \mathrm{C}_{\alpha}, 53.338$ and 52.496; $\mathrm{C}_{\beta}, 31.721 ; \mathrm{C}_{\gamma}, 29.719 ; \mathrm{C}\left(\mathrm{CH}_{3}\right)_{3}, 28.131$ and 28.051; $\mathrm{SCH}_{2} \mathrm{D}, 14.931$ ( $\mathrm{t}, J=21.075 \mathrm{~Hz}$ ). High resolution ESI-TOF-MS $\left(\mathrm{C}_{10} \mathrm{H}_{18} \mathrm{O}_{4} \mathrm{NSD}, \mathrm{MNa}^{+}\right.$calc $273.0989, \mathrm{MNa}^{+}{ }_{\text {obs }}$ 273.0985). Both ${ }^{13} \mathrm{C}$ and ${ }^{1} \mathrm{H}$ NMR indicate that there are $\mathrm{H}-$ bonded conformations in the absence of a methyl ester.

Solid phase peptide synthesis (SPPS). Peptides were prepared by manual SPPS typically on a $0.2 \mathrm{mmol}$ scale by using the in situ neutralization/HBTU activation procedure for Boc chemistry as described by Schnölzer et al. ${ }^{3}$ Peptide was cleaved from the resin $(\sim 300 \mathrm{mg})$ with $\mathrm{HF}(\sim 10 \mathrm{~mL})$ and anisole $(0.5 \mathrm{~mL})$ at $4{ }^{\circ} \mathrm{C}$ for 1 hour. Ice-cold ether $(\sim 100 \mathrm{~mL})$ was used to precipitate the peptide, which was filtered and dissolved into a solution of $30 \%$ acetonitrile in water $(\sim 100$ $\mathrm{mL})$. The mixture was lyophilized, dissolved in $50 \%$ acetic acid, and purified by preparative HPLC.

Protein Synthesis. Labeled methionine was incorporated into cyt $c$ at position 80 using a semi-synthetic strategy previously reported ${ }^{4,5,6}$ and briefly stated here. Horse heart cyt $c$ was cleaved by way of $\mathrm{CNBr}$ digest. The 1-65 fragment $\left(\mathrm{f}_{\mathrm{N}}\right)$ was purified by HPLC and lyophilized. The 66-104 fragment $\left(f_{C}\right)$ was made by SPPS, where labeled methionine was incorporated during SPPS. The two fragments $\left(f_{\mathrm{N}} \sim 53\right.$ $\mathrm{mg}, \mathrm{f}_{\mathrm{C}} \sim 30 \mathrm{mg}$ ) were ligated to produce cyt $c$ with a homoserine (hSer) at position 65 , Met65hSer. The protein was purified with a Sephadex G-50 column (Amersham Biosciences) in $7 \%$ formic acid(aq), oxidized with bis(dipicolinato)cobaltate (III), ${ }^{7}$ and desalted with a Sephadex

(3) Schnölzer, M.; Alewood, P.; Jones, A.; Alewood, D.; Kent, S. B. H. Int. J. Pept. Protein Res. 1992, 40, 180.

(4) Sagle, L. B.; Zimmermann, J.; Dawson, P. E.; Romesberg, F. E. J. Am. Chem. Soc. 2004, 126, 3384-3385.

(5) Wallace, C. J. A.; Offord, R. E. Biochem. J. 1979, 179, 169-182.

(6) Wallace, C. J. A.; Clark-Lewis, I.; J. Biol. Chem. 1992, 267, 3852-3861.

(7) Mauk, A. G.; Coyle, C. L.; Bordignon, E.; Gray, H. B. J. Am. Chem. Soc. 1979, 101, 5054-5056. 


\title{
Efforts Toward Developing Direct Probes of Protein Dynamics
}

\author{
Matthew E. Cremeens, ${ }^{\dagger}$ Hiroshi Fujisaki, ${ }^{\ddagger}$ Yong Zhang, ${ }^{\ddagger}$ Jörg Zimmermann, ${ }^{\dagger}$ Laura B. Sagle ${ }^{\dagger}$ \\ Shigeo Matsuda, ${ }^{\dagger}$ Philip E. Dawson, ${ }^{\dagger}$ John E. Straub, ${ }^{\dagger}$ and Floyd E. Romesberg ${ }^{\dagger *}$ \\ ${ }^{\dagger}$ Department of Chemistry, The Scripps Research Institute, 10550 North Torrey Pines Road, La Jolla, CA \\ 92037 and Department of Chemistry, Boston University, 590 Commonwealth Avenue, Boston, MA 02215
}

G-25 column. The protein was washed (5 mM NaOAc, $\mathrm{pH}$ 5) and concentrated with a 10,000 MW cutoff Amicon-Ultra concentrator. Met80- $d_{3}$ semi-synthesis has been reported. Sequence: Acetyl-GDVEKGKKIF-VQKCAQCHTVEKGGKHKTGP-NLHGLFGRKT-GQAPGFTYTD-ANKNKGITWKEETLXEYLEN-PKKYIPGTKM-IFAGIKKKTE-REDLIAYLKK-

ATNE where $\mathrm{x}=$ hSer and the heme $\left(\mathrm{C}_{34} \mathrm{H}_{34} \mathrm{~N}_{4} \mathrm{O}_{4} \mathrm{Fe}\right)$ is covalently attached at Cys14 and Cys17. The $\mathrm{M}_{\text {calc }}$ for Met80- $d_{1}$ was $12,330.8 \mathrm{Da}$ and from EI/MS the $\mathrm{M}_{\text {obs }}$ was $12,328.6 \pm 1.3 \mathrm{Da}$ (Figure S-1).

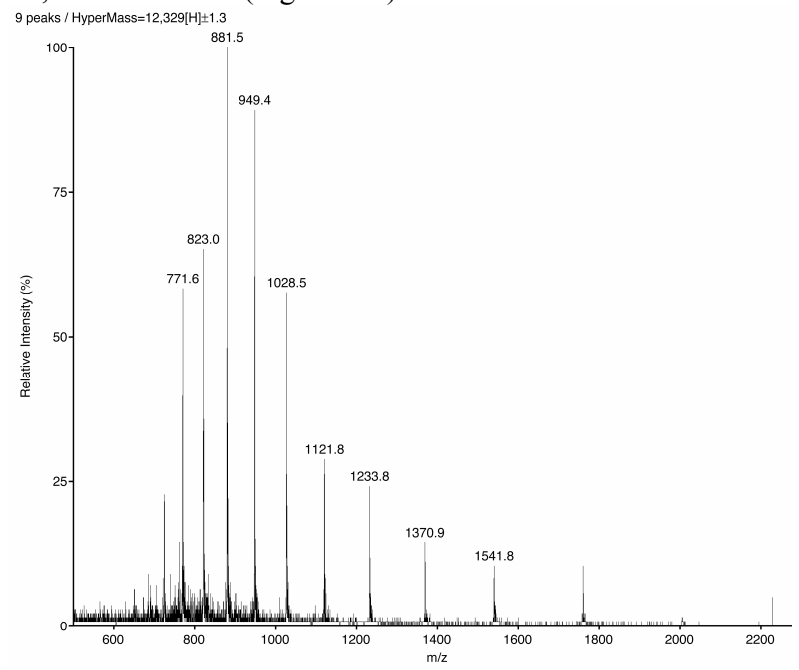

Figure S-1. ES/MS of Met80- $d_{1}$.

Sample Handling. Thin films of Boc-Met- $d_{0}$, Boc-Met- $d_{1}$, and Boc-Met- $d_{3}$ were prepared by making $100 \mathrm{mM}$ solutions in benzene, aliquoting $40 \mu \mathrm{L}$ onto a $\mathrm{CaF}_{2}$ disc, and removing benzene by placing the disc into a vacuum chamber. Measurements of Boc-Met- $d_{0}$, Boc-Met- $d_{1}$, and Boc-Met- $d_{3}$ in buffer (100 mM NaOAc, $\mathrm{pH} 5)$ had sample concentrations of $100 \mathrm{mM}$. For Met80- $d_{1}$ and Met80- $d_{3}$, sample concentrations were $6-7 \mathrm{mM}$ and $10 \mathrm{mM}$, respectively, in the same buffer. A liquid sample cell (PIKE; Madison, WI), $\mathrm{CaF}_{2}$ $\operatorname{discs}(13 \times 2 \mathrm{~mm})$, and a $50 \mu \mathrm{m}$ Teflon spacer were used to house the solutions. The instrument chamber was continuously purged with $\mathrm{N}_{2}(\mathrm{~g})$ (14 psi) from a low pressure $\mathrm{N}_{2}(\mathrm{l})$ tank that was passed over molecular sieves and $\mathrm{Ca}_{2} \mathrm{SO}_{4}$. After opening the chamber to mount the sample, the chamber was purged for 15-20 minutes before acquiring data.

Data Acquisition Settings. A Bruker Equinox 55 FT-IR instrument was interfaced with the OPUS program supplied by Bruker Optics. For measurements of Boc-Met- $d_{1} /$ Boc-Met$d_{0}$, Boc-Met- $d_{3} /$ Boc-Met- $d_{0}$, and Met80- $d_{3} /$ Met $80-d_{0}, 8,192$ scans were acquired. For measurements of Met80- $d_{1} /$ Met80$d_{0}, 81,920$ scans were acquired. Fourier transform parameters: a Blackman-Harris 3-term (BH3) apodization function, phase resolution set to 32 , the phase correction mode set to power spectrum, zero filling factor of 16. Optic parameters: MIR source, $\mathrm{KBr}$ beamsplitter, scanner velocity of $60 \mathrm{KHz}$, liquid $\mathrm{N}_{2}$ cooled MCT detector, low pass filter at $16 \mathrm{KHz}$, iris aperture of 1900 microns, and signal gain set to automatic.

Data Acquisition: Apodization and Resolution. Depending on the instrument resolution (R) and the linewidth or full width at half maximum $(\Gamma)$ of the band, an apodization function can broaden the observed absorption. ${ }^{8}$ A weaker apodization function exhibits less broadening, but the spectrum becomes noisier. As the resolution increases (e.g. from $4 \mathrm{~cm}^{-1}$ to $2 \mathrm{~cm}^{-1}$ ), the signal to noise ratio (SNR) decreases. To achieve reasonable error bars for the observed linewidths, a balance between SNR and apodization broadening must be achieved based upon the strength of the absorption. Since the methyl- $d_{3}$ signal was stronger and narrower than methyl- $d_{1}, 2 \mathrm{~cm}^{-1}$ and $4 \mathrm{~cm}^{-1}$ resolutions were used, respectively.

To quantitatively assess apodization broadening, the $\mathrm{BH} 3$ function was evaluated by establishing a relationship between $\Gamma_{\text {true }} / \Gamma_{\text {obs }}$ and $\Gamma_{\text {obs }} / \mathrm{R}$ (Figure S-2). $\Gamma_{\text {true }}$ can be determined in the absence of an apodization function (i.e. boxcar) for $\Gamma_{\mathrm{obs}} / \mathrm{R}$ $\geq 0.75$, which was accomplished with thin film samples of Boc-Met- $d_{1}$ and Boc-Met- $d_{3}$ at $1,2,4$, and $6 \mathrm{~cm}^{-1}$ resolution. A non-linear relationship $\left(\Gamma_{\text {true }} \approx \Gamma_{\text {obs }}-1.38[R]^{2.30}\left[\Gamma_{\text {obs }}\right]^{-1.30}\right.$ ) shows that $\Gamma_{\text {obs }} / \mathrm{R}$ values above 4.25 yield $\Gamma_{\text {true }} / \Gamma_{\text {obs }}$ values above 0.95 , and more importantly in this regime the relationship behaves linearly such that $\Delta \Gamma_{\text {true }} \approx 0.96 \times \Delta \Gamma_{\text {obs }}$, which lies within experimental error.

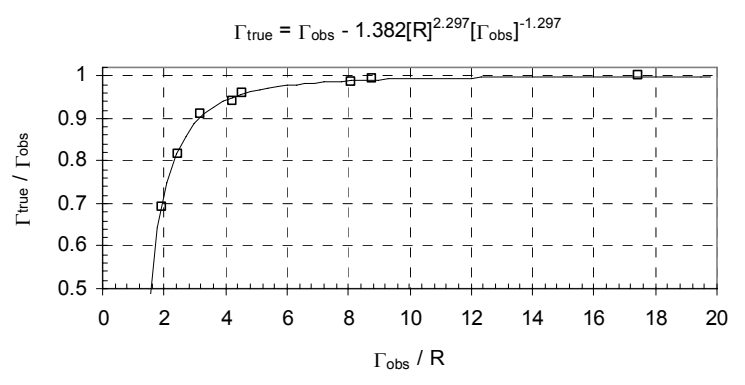

Figure S-2. Graph of $\Gamma_{\text {true }} / \Gamma_{\text {obs }}$ V.s. $\Gamma_{\text {obs }} / \mathrm{R}$.

The instrument resolution was set to $4 \mathrm{~cm}^{-1}$ for Boc-Met- $d_{1}$, where for a single Gaussian fit to the band $\Gamma_{\text {obs }} / \mathrm{R} \sim 9.5$ and for Met80- $d_{1} \Gamma_{\text {obs }} / \mathrm{R} \sim 3.75$. The SNR for Met80- $d_{1}$ data acquired at $2 \mathrm{~cm}^{-1}$ resolution was too low to accurately determine the linewidth; for a single Gaussian fit $\Gamma_{\text {obs }}=19 \pm 8$ $\mathrm{cm}^{-1}$ where the standard error mean is at the $95 \%$ confidence level. The instrument resolution was set to $2 \mathrm{~cm}^{-1}$ for the absorption of Met- $d_{3}$, where for the symmetric stretch of BocMet- $d_{3}, \Gamma_{\text {obs }} / \mathrm{R} \sim 4.8$ and for the symmetric stretch of Met80$d_{3}, \Gamma_{\text {obs }} / \mathrm{R} \sim 2.75$. Because this relationship applies to the total band, only linewidths from single Gaussian fits can be corrected according to the above equation. The case that would show the largest effect is presented as an example: the symmetric stretch of Met80- $d_{3}$ goes from $5.5 \pm 0.2$ to $4.8 \pm$ $0.2 \mathrm{~cm}^{-1}$ upon correction. Since this correction is relatively small for the worst case scenario, no further attempt to correct the linewidths was made.

Data Processing: Baseline Correction. For spectra of samples in solution, the proteo spectrum was subtracted from the deutero spectrum over the range of $2600-1875 \mathrm{~cm}^{-1}$

(8) Parker, S. F.; Tooke, P. B. Spectrochim. Acta Part A 1997, 53, 2245-2252. 


\title{
Efforts Toward Developing Direct Probes of Protein Dynamics
}

\author{
Matthew E. Cremeens, ${ }^{\dagger}$ Hiroshi Fujisaki, ${ }^{\ddagger}$ Yong Zhang, ${ }^{\ddagger}$ Jörg Zimmermann, ${ }^{\dagger}$ Laura B. Sagle ${ }^{\dagger}$ \\ Shigeo Matsuda, ${ }^{\dagger}$ Philip E. Dawson, ${ }^{\dagger}$ John E. Straub, ${ }^{\ddagger}$ and Floyd E. Romesberg ${ }^{\dagger *}$ \\ ${ }^{\dagger}$ Department of Chemistry, The Scripps Research Institute, 10550 North Torrey Pines Road, La Jolla, CA \\ 92037 and Department of Chemistry, Boston University, 590 Commonwealth Avenue, Boston, MA 02215
}

using the autosubtract option in OPUS, which produced subtraction factors of $1.00 \pm 0.05$. The effect of the subtraction factor value on the observed results was tested; values different from OPUS by \pm 0.05 did not affect the results (data not shown). The resulting 'deutero - proteo' spectrum was baseline corrected in the following manner. Data was processed in the Matlab 6.5 program with the nonlinear least-squares fitting routine, lsqcurvefit. The baseline was corrected by fitting the sum of an $n^{\text {th }}$ order polynomial and a Gaussian(s) to the data, where the Gaussian(s) approximates the absorption and the $\mathrm{n}^{\text {th }}$ order polynomial approximates the baseline. The polynomial, not the Gaussian(s) approximating the absorption, was subtracted from the data to yield a baseline corrected spectrum (see Figure S-3 for an example). In the Additional Figures section, an averaged spectrum for each absorption is presented.
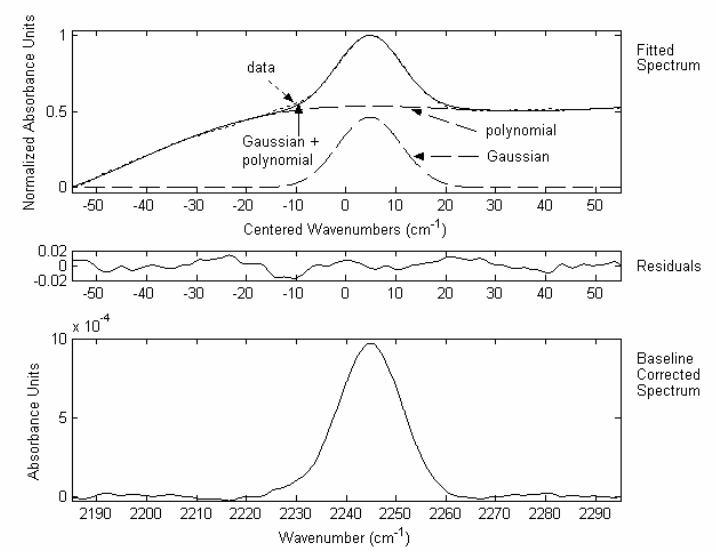

Figure S-3. Example baseline correction. See text for details.

Data Fitting. For overlapping absorptions, the $2^{\text {nd }}$ derivative was determined within the OPUS program to assess the maximum number of functions that may be fit to the observed band. ${ }^{9}$ For each baseline corrected spectrum, one or more functions were fit to the data. When fitting multiple functions to a band, an F-test was performed to determine whether an additional function was statistically significant. ${ }^{10}$ To obtain error bars for linewidths from multiple function fits, the averaged spectrum was fit and the relative amplitudes were noted. Then, each spectrum contributing to the average was fit to a sum of functions set to the relative amplitude acquired from the averaged spectrum. The spectra were acquired under conditions mimicking a previous paper; ${ }^{11}$ recently it was shown that the protein is slightly unfolded $(12 \pm 3 \%)$ at Met80 under these conditions. ${ }^{12}$ The Met $80-d_{3}$ spectra were corrected for the unfolded contribution. For Met $80-d_{1}$, the unfolded absorption is so broad and weak in

(9) Smith, B. C. Fundamentals of Fourier Transform Infrared Spectroscopy. CRC Press: New York, 1996; Chapter 3.

(10) Gans, P. Data Fitting in the Chemical Sciences. John Wiley \& Sons: New York, 1992; Chapter 6.

(11) Chin, J. K.; Jimenez, R.; Romesberg, F. E. J. Am. Chem. Soc. 2001, 123, 2426-2427.

(12) Sagle, L. B.; Zimmermann, J.; Dawson, P. E.; Romesberg, F. E. unpublished results 2006 . amplitude that its contribution to the observed spectrum after baseline correction was deemed negligible.

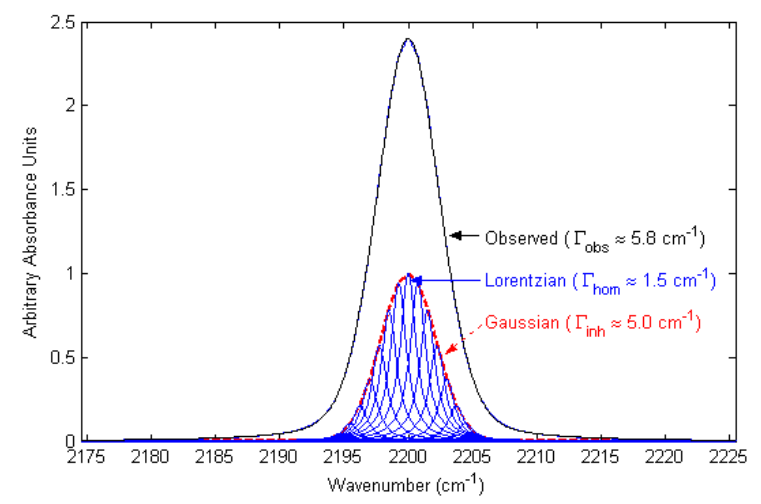

Figure S-4. Example: convolution of Lorentzian and Gaussian functions. A sum of Lorentzians in a Gaussian distribution yields $\Gamma_{\text {obs. }}$. For this example, $\Gamma_{\text {inh }}=5.0 \mathrm{~cm}^{-1}, \Gamma_{\text {hom }}=1.5 \mathrm{~cm}^{-1}, \Gamma_{\mathrm{obs}}=5.8 \mathrm{~cm}^{-1}$.

Data Analysis: Voigt function. A convolution ${ }^{13}$ of Lorentzian (homogeneous, $\Gamma_{\text {hom }}$ ) and Gaussian (inhomogeneous, $\Gamma_{\text {inh }}$ ) components produces a profile (observed, $\left.\Gamma_{\text {obs }}\right),{ }^{14}$ which can be deconvoluted with a Voigt function (Figure S-4). ${ }^{15}$ Since the Voigt function involves an integral, it is convenient to use an approximate analytic function ${ }^{16}$ to show the relation of the components, $\Gamma_{\mathrm{inh}} / \Gamma_{\mathrm{obs}}=$ $\left[1-\Gamma_{\text {hom }} / \Gamma_{\text {obs }}\right]^{1 / \alpha}$ where $\alpha \approx 2$. A slightly better approximation $(\alpha \approx 1.925)$ arises when fitting this function to tabulated values $^{17}$ from a Voigt profile. Plotting this equation allows one to visualize the relationship between $\Gamma_{\text {inh }} / \Gamma_{\text {obs }}$ and $\Gamma_{\text {hom }} / \Gamma_{\text {obs }}$ (Figure S-5). Note that Voigt-fits of spectra, which were baseline corrected with a Gaussian function and polynomial, provide an upper limit for $\Gamma_{\text {inh }}$ and therefore a lower limit for $\Gamma_{\text {hom }}$ values.
(13) A convolution is an integral that blends one function with another; it expresses the amount of overlap of one function as it is shifted over another function.

(14) (a) Kubo, R.. Adv. Chem. Phys. 1969, 15, 101-127. (b) Schmidt, J. R.; Sundlass, N.; Skinner, J. L. Chem. Phys. Lett. 2003, 378, $559-566$.

(15) Asthana, B. P.; Kiefer, W. Appl. Spectrosc. 1982, 36, 250-257. This paper lists the Voigt function and discusses reference 16.

(16) Tanabe, K.; Hiraishi, J. Spectrochim. Acta A 1980, 36, 341-344.

(17) Bakshi, V.; Kearney, R. J. J. Quant. Spectrosc. Radiat. Transfer 1989, 42, 111-115. On page 113 , b1 should be b2 and vice versa. Personal communication Vivek Bakshi, 2005. 


\section{Efforts Toward Developing Direct Probes of Protein Dynamics}

Matthew E. Cremeens, ${ }^{\dagger}$ Hiroshi Fujisaki, ${ }^{\ddagger}$ Yong Zhang, ${ }^{\ddagger}$ Jörg Zimmermann, ${ }^{\dagger}$ Laura B. Sagle ${ }^{\dagger}$ Shigeo Matsuda, ${ }^{\dagger}$ Philip E. Dawson, ${ }^{\dagger}$ John E. Straub,${ }^{\ddagger}$ and Floyd E. Romesberg ${ }^{\dagger *}$

${ }^{\dagger}$ Department of Chemistry, The Scripps Research Institute, 10550 North Torrey Pines Road, La Jolla, CA 92037 and Department of Chemistry, Boston University, 590 Commonwealth Avenue, Boston, MA 02215
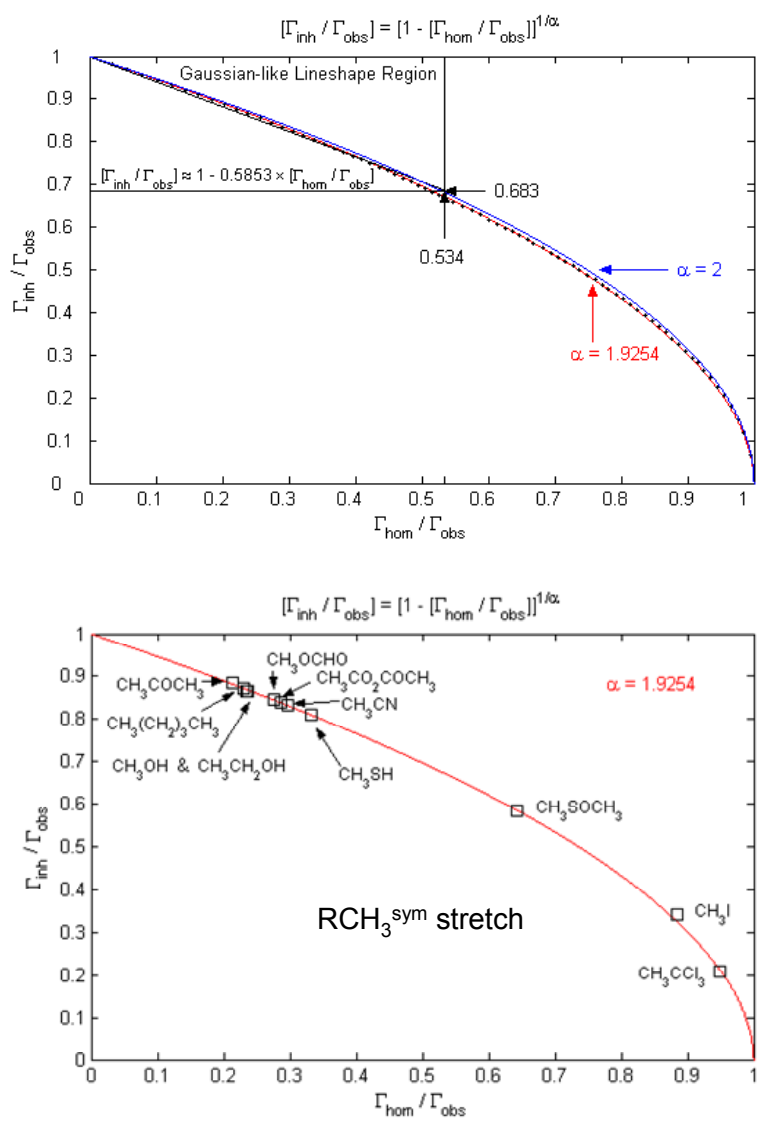

Figure S-5. (top) Analytic function approximating the relationship between $\Gamma_{\text {inh }} / \Gamma_{\text {obs }}$ and $\Gamma_{\text {hom }} / \Gamma_{\text {obs }}$ for a Voigt profile. The blue line $(\alpha=$ 2 ) was empirically derived by Tanabe and Hiraishi (ref 16), while the red line $(\alpha=1.925)$ resulted from a fit to tabulated values (black dots) from a Voigt profile (ref 17). Note: in the Gaussian-like lineshape region where a Gaussian- $\mathrm{ft}$ is better than a Lorentzian-fit, the relationship can be approximated as linear, $\Gamma_{\mathrm{obs}} \approx \Gamma_{\mathrm{inh}}+0.585 \Gamma_{\mathrm{hom}}$ and the maximum possible $\Gamma_{\text {hom }}$ is $0.534 \Gamma_{\text {obs. }}$. (bottom) Experimental results were taken from George, S. M.; Auweter, H.; Harris, C. B. J. Chem. Phys. 1980, 73, 5573-5583.

Data Analysis: Baseline Correction Effects. For spectra that were baseline corrected with a sum of a Gaussian(s) and polynomial, Gaussian-fits were noticeably better than Lorentzian-fits (except for $\mathrm{CD}_{3}{ }^{\text {sym }}$ of Boc-Met). In an attempt to examine the degree to which this result was an artifact of baseline correction with a Gaussian function, baseline correction was performed with a linear combination of Gaussian and Lorentzian functions (G-L function). ${ }^{18}$ For the relationship of $\mathrm{f}$ (fraction Gaussian) and $\Gamma_{\mathrm{obs}}$ in equation 3 (reference 18) to $\Gamma_{\text {hom }}$ and $\Gamma_{\text {inh }}$ see Figure S-6. In principle, Voigt-fits for spectra that were baseline corrected with a sum of a G-L function and polynomial should yield more accurate estimations for $\Gamma_{\text {hom }}$.

(18) Equation (3) in Fraser, R. D. B.; Suzuki, E. Anal. Chem. 1969, $41,37-39$.

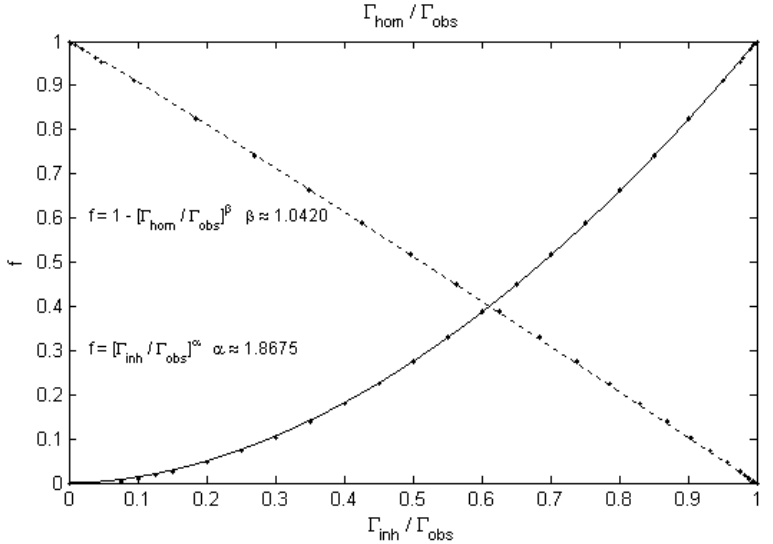

Figure S-6. Equation 3 of reference 18 is a linear combination of Gaussian and Lorentzian functions that yields the fraction (f) Gaussian and the total linewidth $\left(\Gamma_{\mathrm{obs}}\right)$. Note: $\Gamma_{\mathrm{obs}}=\Gamma_{\text {total }}, \Gamma_{\mathrm{inh}}=\Gamma_{\mathrm{Gauss}}$, and $\Gamma_{\text {hom }}=\Gamma_{\text {Lorent. }}$. By fitting this equation to various Voigt profiles (dots), one can establish an approximate relationship between the obtained values ( $f$ and $\Gamma_{\text {obs }}$ ) using an analytic function and the desired values $\left(\Gamma_{\text {hom }}\right.$ and $\left.\Gamma_{\text {inh }}\right)$ using the Voigt function. The results are plotted above where $\mathrm{f}=1-\left[\Gamma_{\mathrm{hom}} / \Gamma_{\mathrm{obs}}\right]^{\beta}$ (dashed line) and $\mathrm{f}=\left[\Gamma_{\text {inh }} / \Gamma_{\mathrm{obs}}\right]^{\alpha}$ (solid line) with $\beta \approx 1.0420$ and $\alpha \approx 1.8675$. Consequently, one does not need to perform a cumbersome Voigt-fit to obtain $\Gamma_{\text {hom }}$ and $\Gamma_{\text {inh. }}$.

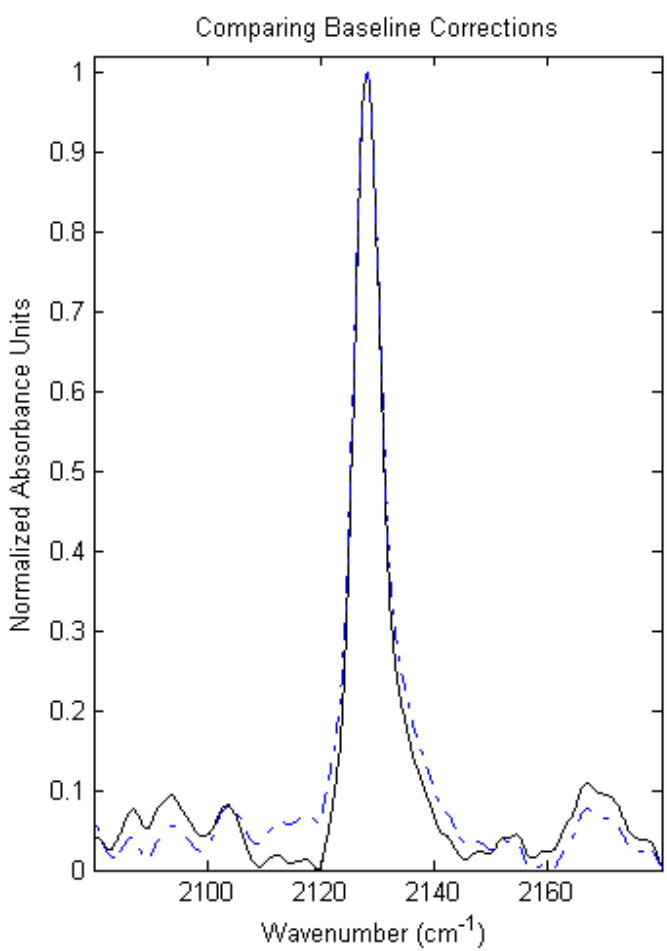

Figure S-7. Comparison of baseline corrections for $\mathrm{CD}_{3}{ }^{\text {sym }}$ of Met80$d_{3}$. Blue dashed line: baseline correction with a G-L function (equation 3, ref 16) and polynomial. Black solid line: baseline correction with a Gaussian function and polynomial. Note the slight difference between the absorptions' feet.

Baseline correction with a polynomial and a G-L function along with subsequent Voigt-fits of the symmetric stretch for Boc-Met- $d_{3}$ and Met80- $d_{3}$ gave values for $\Gamma_{\text {hom }}$ of 7.7 and 2.5 


\title{
Efforts Toward Developing Direct Probes of Protein Dynamics
}

\author{
Matthew E. Cremeens, ${ }^{\dagger}$ Hiroshi Fujisaki, ${ }^{\ddagger}$ Yong Zhang, ${ }^{\ddagger}$ Jörg Zimmermann, ${ }^{\dagger}$ Laura B. Sagle ${ }^{\dagger}$ \\ Shigeo Matsuda, ${ }^{\dagger}$ Philip E. Dawson, ${ }^{\dagger}$ John E. Straub, ${ }^{\dagger}$ and Floyd E. Romesberg ${ }^{\dagger *}$ \\ ${ }^{\dagger}$ Department of Chemistry, The Scripps Research Institute, 10550 North Torrey Pines Road, La Jolla, CA \\ 92037 and Department of Chemistry, Boston University, 590 Commonwealth Avenue, Boston, MA 02215
}

$\mathrm{cm}^{-1}$, respectively. Figure S-7 illustrates the small changes to the absorption's feet due to the method of baseline correction; Voigt-fits are very sensitive to these small differences. All attempts to baseline correct and then fit Boc-Met- $d_{1}$ in a similar manner gave nonsensical results. This likely resulted from the large number of free parameters needed for a three Voigt function fit and the extreme sensitivity of such fits to minor changes in the absorption's feet. Consequently, this approach to baseline correction was not used because all spectra need to be treated in a similar manner.

Data Analysis: Degree of Homogeneous Broadening. Estimating $\Gamma_{\text {hom }}$ is desired because it yields $T_{2}$, the total homogeneous dephasing time, and $\mathrm{T}_{2}$ can be related to $\mathrm{T}_{1}$, the vibrational relaxation time. $\Gamma_{\text {hom }}=1 /\left(\pi \mathrm{cT} \mathrm{T}_{2}\right)$ and one can write $1 /\left(T_{2}\right)=1 /\left(2 T_{1}\right)+1 /\left(T_{2} *\right)$ where $1 / T_{2} *$ is the pure dephasing rate. The absolute limits for $\Gamma_{\text {hom }}, \mathrm{T}_{2}$, and $\mathrm{T}_{1}$ are below (lines 1-3), where the minimum value for $T_{1}$ arises from setting $1 /\left(\mathrm{T}_{2}{ }^{*}\right) \approx 0$ so that $\mathrm{T}_{1} \geq 1 / 2 \mathrm{~T}_{2}$ (alternatively written as $\mathrm{T}_{1} \geq$ $\left.1 /\left(2 \pi \mathrm{c} \Gamma_{\text {hom }}\right)\right)$. In the absence of deconvolution, one way to estimate the minimum and maximum $\Gamma_{\text {hom }}$ arises from a simple criterion (see Figure S-5). If a Lorentzian-fit is better than a Gaussian-fit, then the minimum $\Gamma_{\text {hom }}$ is $0.534 \Gamma_{\text {obs }}$ (line 4), and if a Gaussian-fit is better than a Lorentzian-fit, then the maximum $\Gamma_{\text {hom }}$ is $0.534 \Gamma_{\text {obs }}$ (line 5). Estimated minimum and maximum values of $\Gamma_{\text {hom }}$ can be obtained from deconvolution of spectra that were baseline corrected with a Gaussian(s) plus polynomial ( $\max \Gamma_{\text {inh }}$ and $\min \Gamma_{\text {hom }}$, line 6) or a Lorentzian(s) plus polynomial $\left(\min \Gamma_{\text {inh }}\right.$ and $\max \Gamma_{\text {hom }}$, line 7), respectively.

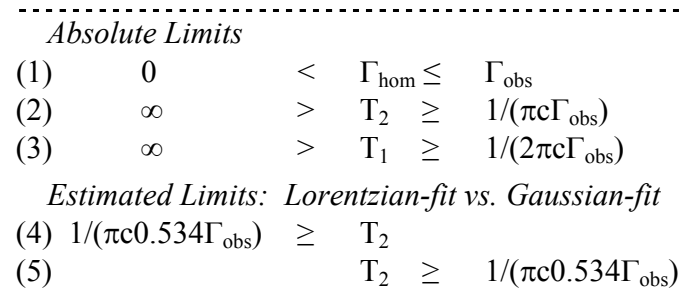

Estimated Limits: Gaussian or Lorentzian Baseline Corrections and Voigt Deconvolution

(6) $1 /\left(\pi \mathrm{c} \Gamma_{\text {hom }}^{\text {min }}\right) \geq T_{2}$

\section{Estimated Ranges}

(8) $1 /\left(2 \pi \mathrm{c} \Gamma_{\text {hom }}^{\text {min }}\right) \geq T_{1} \geq 1 /\left(2 \pi \mathrm{c} \Gamma_{\text {obs }}\right)$ (9) $1 /\left(2 \pi \mathrm{c} \Gamma_{\text {hom }}^{\text {min }}\right) \geq T_{1} \geq 1 /\left(2 \pi \mathrm{c} 0.534 \Gamma_{\text {obs }}\right)$

In principle, spectra that were baseline corrected with the G-L function plus polynomial more accurately estimate $\Gamma_{\text {hom }}$ and should lie within any of the min and max values established above. In practice, this approach becomes less robust with overlapping absorptions; consequently one wants to establish a range of possible values. The limits established below are presented in order of increasing numerical effort which correlates to improved estimates. In this study, we deconvoluted the spectra to estimate $\Gamma_{\text {hom }}{ }^{\text {min }}$ but not $\Gamma_{\text {hom }}{ }^{\text {max }}$; consequently, for an estimated range we are left with line 8 when a Lorentzian-fit is better than a Gaussian-fit and line 9 when a Gaussian-fit is better fit than a Lorentzian-fit.
To illustrate these points, $\Gamma_{\text {hom }}$ of the Boc-Met- $d_{3}$ symmetric stretch has an absolute range of $0-9.6 \mathrm{~cm}^{-1}$, an estimated range (line 8 ) of $5.7-9.6 \mathrm{~cm}^{-1}$, and an approximate value of $7.7 \mathrm{~cm}^{-1}$ after baseline correction with the G-L function and Voigt deconvolution. This translates into $T_{2}$ values with an absolute range of $\infty-1.1 \mathrm{ps,}$, an estimated range of $1.9-1.1 \mathrm{ps}$, and an approximate value of $1.4 \mathrm{ps}$. Using the $T_{1} \geq 1 / 2 T_{2}$ approximation, $T_{1}$ values have an absolute range of $\infty-0.55 \mathrm{ps}$, an estimated range of $0.93-$ $0.55 \mathrm{ps}$, and an approximate value of $0.69 \mathrm{ps}$. Also, $\Gamma_{\text {hom }}$ of the Met80- $d_{3}$ symmetric stretch has an absolute range of $0-$ $5.5 \mathrm{~cm}^{-1}$, an estimated range (line 9) of $0.3-2.9 \mathrm{~cm}^{-1}$, and an approximate value of $2.5 \mathrm{~cm}^{-1}$ after baseline correction with the G-L function and Voigt deconvolution. This translates into $\mathrm{T}_{2}$ values with an absolute range of $\infty-1.9 \mathrm{ps}$, an estimated range of $35-3.6 \mathrm{ps}$, and an approximate value of $4.2 \mathrm{ps}$. Using the $T_{1} \geq 1 / 2 T_{2}$ approximation, $T_{1}$ values have an absolute range of $\infty-1.0 \mathrm{ps}$, an estimated range of $18-1.8$ ps, and an approximate value of $2.1 \mathrm{ps}$.

Quantum Chemical Calculations. Quantum chemical normal mode anharmonic frequency calculations ${ }^{19}$ of Met- $d_{1}$ and Met- $d_{3}$ were performed in Gausian $03^{20}$ at the B3LYP/6$31+\mathrm{G}(\mathrm{d}, \mathrm{p})$ level of theory (unless stated otherwise) for aiding band assignments. In Gaussian03, anharmonic frequency calculations automatically include Fermi resonances, ${ }^{9}$ which affect the predicted frequencies. Because the chosen basis set inconsistently impacted the presence or absence of resonances with the stretching modes (data not shown), all resonances for C-D stretching modes were removed. The resulting values were used as the predicted frequencies for comparison to experiment. Preceding the anharmonic frequency corrections, harmonic normal mode calculations and predicted intensities are reported. For accurate intensity predictions, highly correlated levels of theory coupled with extensive basis sets are required. ${ }^{21,22}$ These conclusions were drawn from tests with small molecules (1-3 heavy atoms), but our concern is for Met ( 9 heavy atoms) where such calculations are not currently feasible. Consequently, predicted IR intensities for

(19) Barone, V. J. Chem. Phys. 2005, 122, 14108

(20) Gaussian 03 (Revision B.05) Frisch, M. J.; Trucks, G. W.; Schlegel, H. B.; Scuseria, G. E.; Robb, M. A.; Cheeseman, J. R.; Montgomery, J. A.; Vreven, Jr., T.; Kudin, K. N.; Burant, J. C.; Millam, J. M.; Iyengar, S. S.; Tomasi, J.; Barone, V.; Mennucci, B.; Cossi, M.; Scalmani, G.; Rega, N.; Petersson, G. A.; Nakatsuji, H.; Hada, M.; Ehara, M.; Toyota, K.; Fukuda, R.; Hasegawa, J.; Ishida, M.; Nakajima, T.; Honda, Y.; Kitao, O.; Nakai, H.; Klene, M.; Li, X.; Knox, J. E.; Hratchian, H. P.; Cross, J. B.; Adamo, C.; Jaramillo, J.; Gomperts, R.; Stratmann, R. E.; Yazyev, O.; Austin, A. J.; Cammi, R.; Pomelli, C.; Ochterski, J. W.; Ayala, P. Y.; Morokuma, K.; Voth, G. A.; Salvador, P.; Dannenberg, J. J.; Zakrzewski, V. G.; Dapprich, S.; Daniels, A. D.; Strain, M. C.; Farkas, O.; Malick, D. K.; Rabuck, A. D.; Raghavachari, K.; Foresman, J. B.; Ortiz, J. V.; Cui, Q.; Baboul, A. G.; Clifford, S.; Cioslowski, J.; Stefanov, B. B.; Liu, G.; Liashenko, A.; Piskorz, P.; Komaromi, I.; Martin, R. L.; Fox, D. J.; Keith, T.; Al-Laham, M. A.; Peng, C. Y.; Nanayakkara, A.; Challacombe, M.; Gill, P. M. W.; Johnson, B.; Chen, W.; Wong, M. W.; Gonzalez, C.; Pople, J. A. Gaussian, Inc., Pittsburgh PA, 2003.

(21) Galabov, B.; Yamaguchi, Y.; Remington, R. B.; Schaefer III, H. F. J. Phy. Chem. A 2002, 106, 819-832.

(22) Halls, M. D.; Schlegel, H. B. J. Chem. Phys. 1998, 109, $10587-$ 10593. 


\title{
Efforts Toward Developing Direct Probes of Protein Dynamics
}

\author{
Matthew E. Cremeens, ${ }^{\dagger}$ Hiroshi Fujisaki, ${ }^{\ddagger}$ Yong Zhang, ${ }^{\ddagger}$ Jörg Zimmermann, ${ }^{\dagger}$ Laura B. Sagle ${ }^{\dagger}$ \\ Shigeo Matsuda, ${ }^{\dagger}$ Philip E. Dawson, ${ }^{\dagger}$ John E. Straub, ${ }^{\dagger}$ and Floyd E. Romesberg ${ }^{\dagger *}$ \\ ${ }^{\dagger}$ Department of Chemistry, The Scripps Research Institute, 10550 North Torrey Pines Road, La Jolla, CA \\ 92037 and Department of Chemistry, Boston University, 590 Commonwealth Avenue, Boston, MA 02215
}

the levels of theory used in this work are not discussed; they were only used for illustrative purposes in Figures S-8, S-9, S-10, and S-11.

Absorption Assignments: Met- $\boldsymbol{d}_{1}$. Our literature searches yielded one report of a vibrational spectrum for a compound similar to Met- $d_{1}$, dimethylsulfide- $d_{1}\left(\mathrm{DMS}-d_{1}\right){ }^{23}$ For neat DMS- $d_{1}$, a single strong absorption was reported at $2185 \mathrm{~cm}^{-1}$. A frequency difference between the gauche and anti orientations of the C-D bond with respect to the chain is expected given well known lone pair effects. ${ }^{24}$ For Met- $d_{1}$ in the gas phase, the two gauche orientations of the C-D bond with respect to the chain are far enough away from the chiral center that they ought to be nearly degenerate, which is what the calculations predict for a straight chain orientation of methionine (2198 and $\left.2195 \mathrm{~cm}^{-1}\right)$. Consequently, one might expect to observe two absorptions, one for the gauche orientations and one for the anti orientation. Experimentally, three overlapping absorptions for Boc-Met- $d_{1}$ are observed, and the possible reasons for this observation are discussed below.

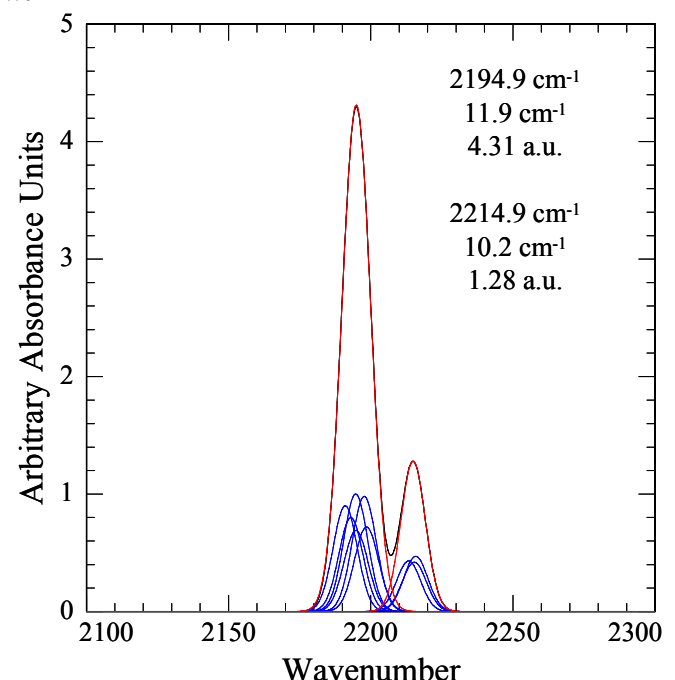

Figure S-8. B3LYP/6-31+G(d,p) Met- $d_{1}$ : Anharmonic v's of the C-D bond in anti and gauche positions for each conformation of the methyl group about the $\mathrm{C}_{\gamma}$-S bond ( 9 total, blue: 6 gauche, 3 anti). Intensities were normalized to the most intense of the nine. The linewidth for each of the nine was set to $10 \mathrm{~cm}^{-1}$. All nine were summed (black) and fit to Gaussians (red) with the fitting results displayed in the figure.

One can estimate the effect of the methyl group rotating about the $\mathrm{C}_{\gamma}-\mathrm{S}$ bond on the C-D frequencies through calculations. The conformations with the methyl group in the two gauche and anti positions are nearly isoenergetic (relative $E_{\text {elec }}$ 's within $0.2 \mathrm{kcal} / \mathrm{mol}$ of each other) and therefore an approximately equal population should exist for the three conformations each with three orientations of the C-D bond giving nine different frequency shifts. A superposition of all nine would be observed. When one uses the calculated

(23) Shiro, Y.; Ohsaku, M.; Hayashi, M.; Murata, H. Bull. Chem. Soc. Japan 1970, 43, 609-618. Three DMS- $d_{1}$ gas phase absorptions were reported but not interpreted.

(24) Bellamy, L.J. The Infrared Spectra of Complex Molecules, Vol 2.; Chapman \& Hall: New York, 1980. frequencies and relative intensities as well as arbitrarily setting a linewidth of $10 \mathrm{~cm}^{-1}$ for each contributing Gaussian, the sum is best fit by only two Gaussians with one representing the sum of six gauche contributions and one representing the sum of three anti contributions (Figure S-8). Consequently, the calculations do not support the notion that methyl group rotation about the $\mathrm{C}_{\gamma}-\mathrm{S}$ bond causes the appearance of three overlapping absorptions.

Another possible rationalization for the appearance of three absorptions comes from the likelihood of $\mathrm{H}$-bonding with the sulfur of Met. One would expect the greatest effect on the frequency difference between the gauche orientations to arise when the sulfur lone pairs are most different, for example when one lone pair is involved in an H-bond and the other is not. In this case there are two categories, intramolecular $\mathrm{H}-$ bonding and intermolecular H-bonding. Consequently, calculations of intramolecular and intermolecular H-bonding effects on the frequency shifts were conducted. A set of calculations for an $\mathrm{N}$-formylated Met, Fm-Met, (a better approximation of Boc-Met than Met) assessed which intramolecular $\mathrm{H}$-bonded species were most favorable. The species with an $\mathrm{N}-\mathrm{H} \cdots \mathrm{S}$ bond were energetically more favorable (in terms of $\mathrm{E}_{\text {elec }}$ at the B3LYP/6-31G(d) level) than those with an $\mathrm{O}-\mathrm{H} \cdots \mathrm{S}$ bond by $\sim 9 \mathrm{kcal} / \mathrm{mol}$ and $2 \mathrm{kcal} / \mathrm{mol}$ more favorable than those without an $\mathrm{N}-\mathrm{H} \cdots \mathrm{S}$ bond. A superposition of results for the $\mathrm{N}-\mathrm{H} \cdots \mathrm{S}$ bonded species at the B3LYP/6-31+G(d,p) level in a manner similar to that stated above was best fit by three Gaussians (Figure S-9).

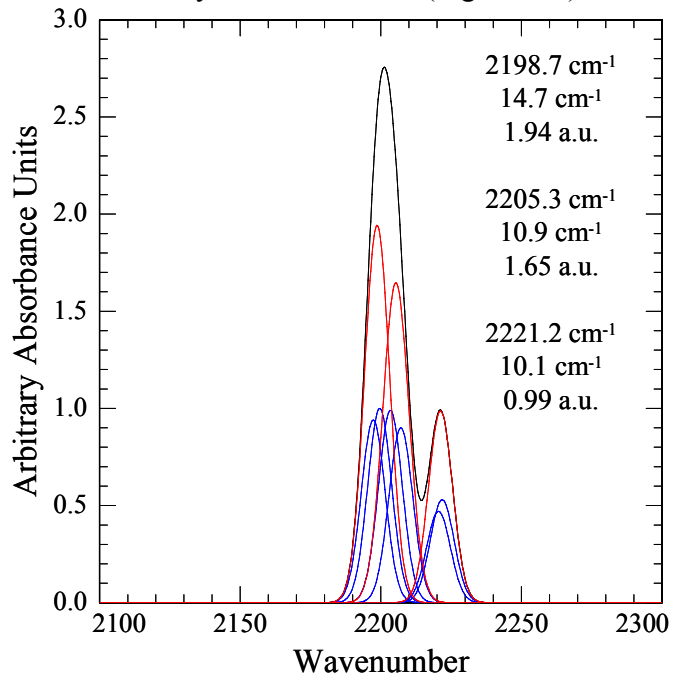

Figure S-9. B3LYP/6-31+G(d,p) Fm-Met- $d_{1}$ N-H $\cdots$. S bond: Anharmonic v's of the C-D bond in anti and gauche positions for each conformation of the methyl group, axial and equatorial, (6 total, blue: 4 gauche and 2 anti). Intensities were normalized to the most intense of the six. Linewidths for each of the six were set to $10 \mathrm{~cm}^{-1}$. All six were summed (black) and fit to Gaussians (red) with the fitting results displayed in the figure.

Calculations for an intermolecular H-bond with $\mathrm{H}_{2} \mathrm{O}$ (HO$\mathrm{H} \cdots \mathrm{S}$ ) proved to be the most informative. Results at the B3LYP/6-31G(d) level of theory predicted a frequency difference for the gauche orientations of $21 \mathrm{~cm}^{-1}$ where the CD bond anti-periplanar to the H-bonded lone pair was 2197 $\mathrm{cm}^{-1}$ and the C-D bond syn-periplanar was $2176 \mathrm{~cm}^{-1}$. The 


\title{
Efforts Toward Developing Direct Probes of Protein Dynamics
}

\author{
Matthew E. Cremeens, ${ }^{\dagger}$ Hiroshi Fujisaki, ${ }^{\ddagger}$ Yong Zhang, ${ }^{\ddagger}$ Jörg Zimmermann, ${ }^{\dagger}$ Laura B. Sagle ${ }^{\dagger}$ \\ Shigeo Matsuda, ${ }^{\dagger}$ Philip E. Dawson, ${ }^{\dagger}$ John E. Straub, ${ }^{\dagger}$ and Floyd E. Romesberg ${ }^{\dagger *}$ \\ ${ }^{\dagger}$ Department of Chemistry, The Scripps Research Institute, 10550 North Torrey Pines Road, La Jolla, CA \\ 92037 and Department of Chemistry, Boston University, 590 Commonwealth Avenue, Boston, MA 02215
}

anti orientation was estimated to be $2226 \mathrm{~cm}^{-1}$. These results support a hypothesis that two of the three observed absorptions arise from gauche orientations and are consistent with the observed results for Met80- $d_{1}$ because both crystal (PDB: 1CRC) and NMR (PDB: 1AKK) structures show an $\mathrm{H}-$ bond between Tyr67 and the sulfur of Met80.

Also, it would be desirable to approximate heme-effects on the C-D bond. However, an estimation of heme-effects with a model system (dimethyl sulfide and imidazole complexed to an iron-heme) at the B3LYP/6-31G(d) and B3LYP/Lan2DZ levels of theory ${ }^{25}$ could not be obtained because anharmonic frequency calculations for such a large system are not currently feasible.

The third possibility, and perhaps the most difficult to rule out, is that one of the absorptions arises from a combination band, which would be in resonance with a stretching mode. Intensity borrowing would give rise to the strength of its signal. Nonetheless, we opt to invoke Occam's razor and hypothesize that the most likely origin for the appearance of two gauche absorptions arises from H-bonding to a sulfur lone pair to create diastereotopic gauche positions.

Absorption Assignments: Met- $\boldsymbol{d}_{3}$. Calculations for the straight chain conformation of Met- $d_{3}$, where one can approximate the $\mathrm{RSCD}_{3}$ group as $\mathrm{C}_{\mathrm{S}}$ symmetric (sym), predicted three absorptions (sym $A^{\prime}$ 2156, asym $A^{\prime \prime} 2231$, and asym $\mathrm{A}^{\prime} 2248 \mathrm{~cm}^{-1}$ ). As in the previous section, allowing for rotation about the $\mathrm{C}_{\gamma}-\mathrm{S}$ and creating a superposition of the results (Figure S-10) yields a result similar to that for the straight chain conformation. Likewise, calculations for the intramolecular H-bonded species are shown in Figure S-11 as a superposition of these results. The case of an intermolecular $\mathrm{H}$-bond with $\mathrm{H}_{2} \mathrm{O}$ at the $\mathrm{B} 3 \mathrm{LYP} / 6-31 \mathrm{G}(\mathrm{d})$ predicted $2155 \mathrm{~cm}^{-}$ ${ }^{1}$ for sym $\mathrm{A}^{\prime}, 2244 \mathrm{~cm}^{-1}$ for asym $\mathrm{A}^{\prime \prime}$, and $2256 \mathrm{~cm}^{-1}$ for asym $A^{\prime}$. Experimentally, for Boc-Met- $d_{3}$ a band at $2135 \mathrm{~cm}^{-}$ 1 appears and is assigned as the symmetric stretch. The discrepancy of $\sim 20 \mathrm{~cm}^{-1}$ between the predicted and observed for symmetric stretches of $\mathrm{RCH}_{3}\left(\mathrm{RCD}_{3}\right)$ appears to be common as exemplified in the case of $\mathrm{CH}_{3} \mathrm{OH}^{26}$ [For a comparison to the results of Yagi et al., anharmonic frequency calculations were conducted for $\mathrm{CH}_{3} \mathrm{OH}$ at the B3LYP level with $6-31 \mathrm{G}(\mathrm{d}), 6-31+\mathrm{G}(\mathrm{d}, \mathrm{p})$, and cc-pVTZ basis sets to respectively yield values for the symmetric stretch 34,19 , and $59 \mathrm{~cm}^{-1}$ above the experimental value, ${ }^{27} 2844 \mathrm{~cm}^{-1}$.] For the asymmetric stretches, the calculations predicted a frequency difference between asym $\mathrm{A}^{\prime}$ and asym $\mathrm{A}^{\prime \prime}$ of $\sim 14 \mathrm{~cm}^{-1}$, but the observed result is a band of overlapping absorptions with less than $2 \mathrm{~cm}^{-1}$ separation when in buffer (Gaussian fitting yields a value $<1 \mathrm{~cm}^{-1}$; the instrument resolution was set to 2 $\mathrm{cm}^{-1}$ ) and $3.5 \mathrm{~cm}^{-1}$ for a thin film sample (2235.8 and 2232.3

(25) Similar methods were used for optimizations of a similar ironheme model system. (a) Kumar, A.; Mishra, P. C.; Verma, C. S.; Renugopalakrishnan, V. Int. J. Quant. Chem. 2005, 102, 10021009. (b) Autenrieth, F.; Tajkhorshid, E.; Baudry, J.; LutheySchulten, Z. J. Comput. Chem. 2004, 25, 1613-1622.

(26) Yagi, K.; Hirao, K.; Taketsugu, T.; Schmidt, M. W.; Gordon, M.S. J. Chem. Phys. 2004, 121, 1383-1389.

(27) Shimanouchi, T., in Tables of Molecular Vibrational Frequencies Consolidated Volume I. National Bureau of Standards, 1972, 1-160. $\mathrm{cm}^{-1}$ with the symmetric stretch at $2128.3 \mathrm{~cm}^{-1}$ ). Similar to Met- $d_{1}$, the possibility of Fermi resonances has not been ruled out.

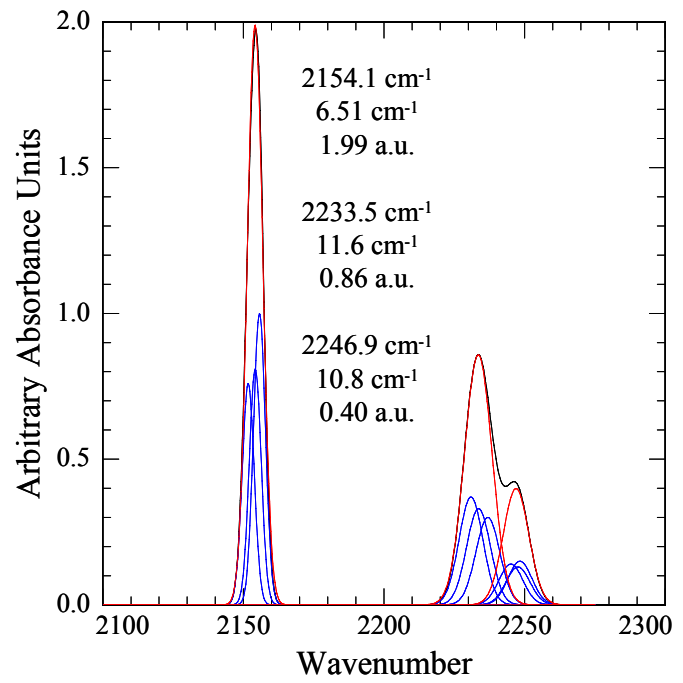

Figure S-10. B3LYP/6-31+G(d,p) Met- $d_{3}$ : Anharmonic $v$ 's of $\mathrm{A}^{\prime}$ sym, $\mathrm{A}^{\prime \prime}$ asym, and $\mathrm{A}^{\prime}$ asym $\mathrm{CD}_{3}$ stretches for each conformation of the methyl group about the $\mathrm{C}_{\gamma}-\mathrm{S}$ bond ( 9 total, blue: $3 \mathrm{~A}^{\prime}$ sym, $3 \mathrm{~A}^{\prime \prime}$ asym, and $3 \mathrm{~A}^{\prime}$ asym). Intensities were normalized to the most intense of the nine. The linewidth for the asym stretches was set to $10 \mathrm{~cm}^{-1}$ and set to $5 \mathrm{~cm}^{-1}$ for the sym stretches. All nine were summed (black) and fit to Gaussians (red) with the fitting results displayed in the figure.

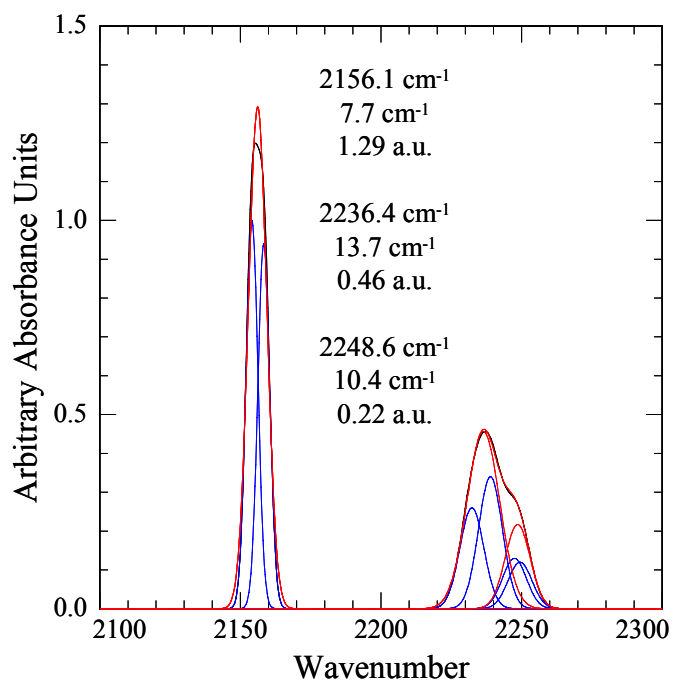

Figure S-11. B3LYP/6-31+G(d,p) Fm-Met $-d_{3} \mathrm{~N}-\mathrm{H} \cdots \mathrm{S}$ bond: Anharmonic $v$ 's of the $\mathrm{A}^{\prime}$ sym, $\mathrm{A}^{\prime \prime}$ asym, and $\mathrm{A}^{\prime}$ asym $\mathrm{CD}_{3}$ stretches for each conformation of the methyl group, axial and equatorial, (6 total, blue: $2 \mathrm{~A}^{\prime}$ sym, $2 \mathrm{~A}^{\prime \prime}$ asym, and $2 \mathrm{~A}^{\prime}$ asym). Intensities were normalized to the most intense of the six. The linewidth for the asym stretches was set to $10 \mathrm{~cm}^{-1}$ and set to $5 \mathrm{~cm}^{-1}$ for the sym stretches. All six were summed (black) and fit to Gaussians (red) with the fitting results displayed in the figure. 


\section{Efforts Toward Developing Direct Probes of Protein Dynamics}

Matthew E. Cremeens, ${ }^{\dagger}$ Hiroshi Fujisaki, ${ }^{\ddagger}$ Yong Zhang, ${ }^{\ddagger}$ Jörg Zimmermann, ${ }^{\dagger}$ Laura B. Sagle ${ }^{\dagger}$ Shigeo Matsuda, ${ }^{\dagger}$ Philip E. Dawson, ${ }^{\dagger}$ John E. Straub,${ }^{\ddagger}$ and Floyd E. Romesberg ${ }^{\dagger *}$

${ }^{\dagger}$ Department of Chemistry, The Scripps Research Institute, 10550 North Torrey Pines Road, La Jolla, CA 92037 and Department of Chemistry, Boston University, 590 Commonwealth Avenue, Boston, MA 02215

Additional Figures. Figures S-12 to S-17 are the average of spectra that were baseline corrected with the sum of a Gaussian(s) and polynomial. Where applicable, Voigt-fits to averaged spectra are presented. Black: data, blue: contributing functions, red: fit.

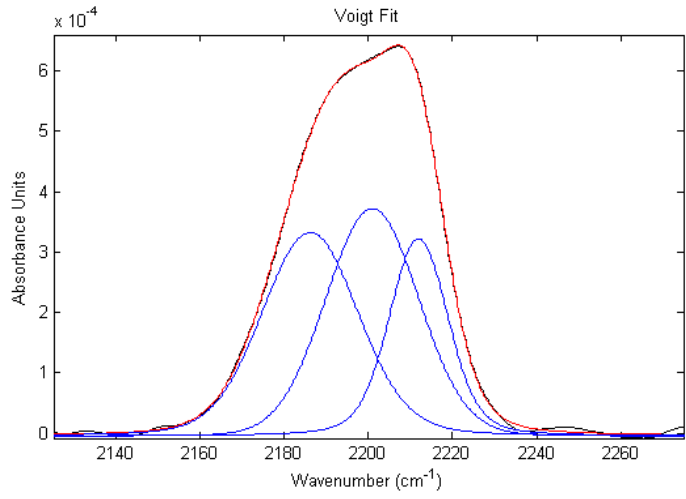

Figure S-12. Boc-Met- $d_{1}$ : average of 6 spectra. Voigt-fit $\left(\mathrm{cm}^{-1}\right)$ : $2186.1\left(\Gamma_{\text {hom }} 4.52, \Gamma_{\text {inh }} 24.57\right), 2200.9\left(\Gamma_{\text {hom }} 1.29 \Gamma_{\text {inh }} 25.4\right), 2211.9$ $\left(\Gamma_{\text {hom }} 4.15 \Gamma_{\text {inh }} 14.2\right)$.

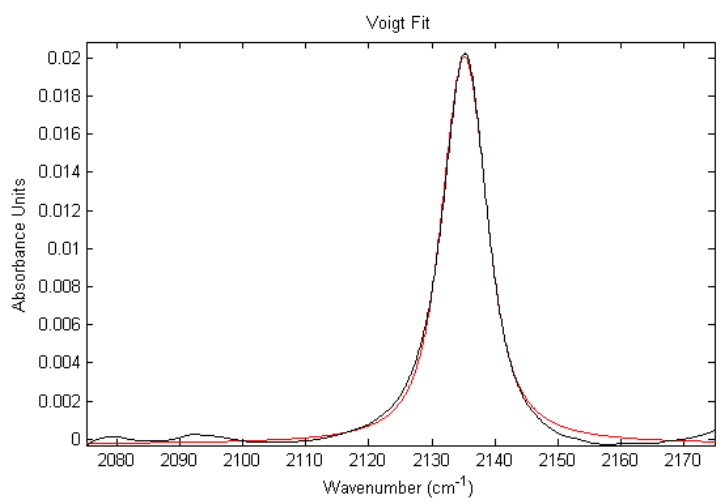

Figure S-13. Boc-Met- $d_{3}$ symmetric band: average of 4 spectra. Voigt-fit $\left(\mathrm{cm}^{-1}\right): 2135.2\left(\Gamma_{\text {hom }} 5.71, \Gamma_{\text {inh }} 4.88\right)$.

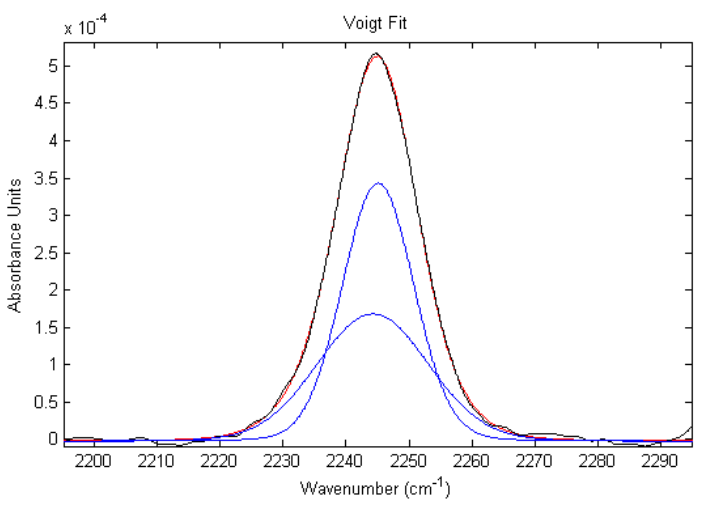

Figure S-14. Boc-Met- $d_{3}$ asymmetric band: average of 4 spectra. Voigt-fit $\left(\mathrm{cm}^{-1}\right): 2244.2\left(\Gamma_{\text {hom }} 1.48, \Gamma_{\text {inh }} 20.1\right), 2245.1\left(\Gamma_{\text {hom }} 0.99 \Gamma_{\text {inh }}\right.$ 12.9).

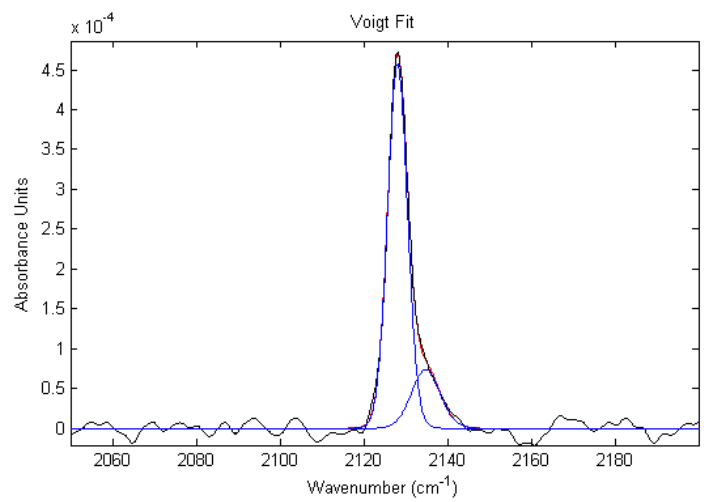

Figure S-15. Met $80-d_{3}$ symmetric band: average of 5 spectra. Voigtfit $\left(\mathrm{cm}^{-1}\right): 2128.1\left(\Gamma_{\text {hom }} 0.30, \Gamma_{\text {inh }} 5.42\right), 2134.8\left(\Gamma_{\text {hom }} 1.44 \Gamma_{\text {inh }} 7.27\right)$

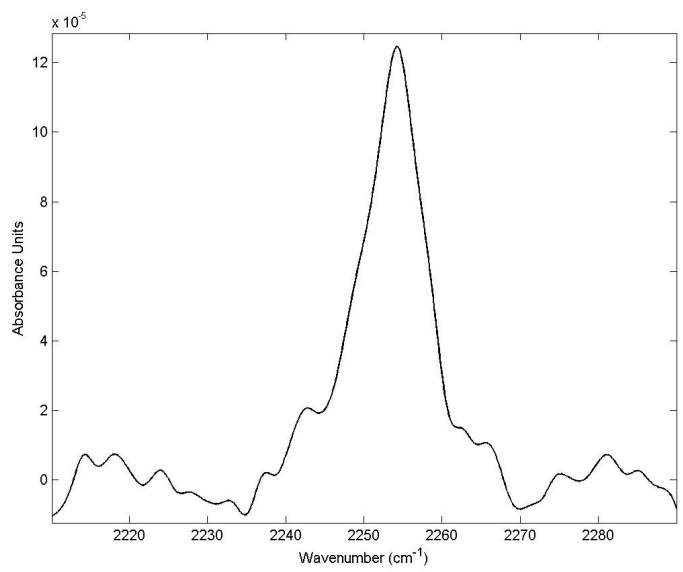

Figure S-16. Met $80-d_{3}$ asymmetric band: average of 5 spectra. The overlapping absorptions could not be resolved, consequently this band was not deconvoluted.

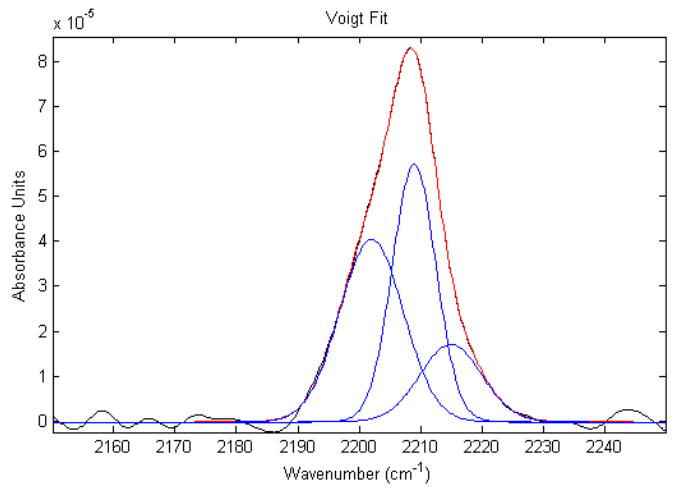

Figure S-17. Met80- $d_{1}$ : average of 9 spectra. Voigt-fit $\left(\mathrm{cm}^{-1}\right): 2202.0$ $\left(\Gamma_{\text {hom }} 0.25, \Gamma_{\text {inh }} 12.1\right), 2209.0\left(\Gamma_{\text {hom }} 0.23 \Gamma_{\text {inh }} 8.27\right), 2215.0\left(\Gamma_{\text {hom }} 0.67\right.$ $\Gamma_{\text {inh }}$ 11.6). 


\section{Efforts Toward Developing Direct Probes of Protein Dynamics}

Matthew E. Cremeens, ${ }^{\dagger}{ }^{+}$Hiroshi Fujisaki, ${ }^{\ddagger}$ Yong Zhang, ${ }^{\ddagger}$ Jörg Zimmermann, ${ }^{\dagger}$ Laura B. Sagle ${ }^{\dagger}$ Shigeo Matsuda, ${ }^{\dagger}$ Philip E. Dawson, ${ }^{\dagger}$ John E. Straub,${ }^{\ddagger}$ and Floyd E. Romesberg ${ }^{\dagger *}$

${ }^{\dagger}$ Department of Chemistry, The Scripps Research Institute, 10550 North Torrey Pines Road, La Jolla, CA 92037 and Department of Chemistry, Boston University, 590 Commonwealth Avenue, Boston, MA 02215

\section{Cartesian coordinates.}

\section{Met: methyl group anti.}

B3LYP/6-31+G(d,p) hf $=-800.5930188$

$\begin{array}{lrrr}\mathrm{H} & 3.323311 & -1.558442 & -0.738637 \\ \mathrm{~N} & 2.428505 & -1.716495 & -0.282804 \\ \mathrm{C} & 1.516384 & -0.601045 & -0.518379 \\ \mathrm{C} & 1.998915 & 0.697097 & 0.135791 \\ \mathrm{C} & 0.114528 & -0.977086 & 0.013853 \\ \mathrm{O} & 1.796551 & 1.786072 & -0.648589 \\ \mathrm{C} & -0.971246 & 0.065573 & -0.265409 \\ \mathrm{~S} & -2.602435 & -0.574619 & 0.287309 \\ \mathrm{C} & -3.644977 & 0.868819 & -0.118718 \\ \mathrm{H} & 2.613260 & -1.811781 & 0.713791 \\ \mathrm{H} & 1.452483 & -0.431119 & -1.598082 \\ \mathrm{O} & 2.507303 & 0.773195 & 1.235192 \\ \mathrm{H} & 0.186688 & -1.158798 & 1.093269 \\ \mathrm{H} & -0.145829 & -1.929674 & -0.458195 \\ \mathrm{H} & -0.768089 & 1.001506 & 0.265753 \\ \mathrm{H} & -1.022606 & 0.289046 & -1.337208 \\ \mathrm{H} & -4.667730 & 0.612557 & 0.167290 \\ \mathrm{H} & -3.333770 & 1.753812 & 0.443930 \\ \mathrm{H} & -3.623347 & 1.085197 & -1.190761\end{array}$

Met: methyl group gauche $B$

$\mathrm{B} 3 \mathrm{LYP} / 6-31+\mathrm{G}(\mathrm{d}, \mathrm{p}) \mathrm{hf}=-800.5932785$

$\begin{array}{lrrr}\mathrm{C} & 2.941623 & -0.388109 & 1.249071 \\ \mathrm{~S} & 2.758413 & 0.076684 & -0.509918 \\ \mathrm{C} & 0.956351 & -0.174360 & -0.751524 \\ \mathrm{C} & 0.075427 & 0.882533 & -0.078276 \\ \mathrm{C} & -1.433351 & 0.741500 & -0.382547 \\ \mathrm{~N} & -2.150198 & 1.864835 & 0.218239 \\ \mathrm{C} & -1.947245 & -0.609283 & 0.123101 \\ \mathrm{O} & -2.142681 & -1.506260 & -0.875334 \\ \mathrm{H} & -3.122675 & 1.879124 & -0.078021 \\ \mathrm{H} & -2.145014 & 1.780449 & 1.232709 \\ \mathrm{H} & -1.584515 & 0.778821 & -1.466078 \\ \mathrm{O} & -2.164600 & -0.874335 & 1.288100 \\ \mathrm{H} & 0.372911 & 1.880915 & -0.411935 \\ \mathrm{H} & 0.208308 & 0.851118 & 1.009984 \\ \mathrm{H} & 0.819079 & -0.150125 & -1.837969 \\ \mathrm{H} & 0.705166 & -1.188161 & -0.420632 \\ \mathrm{H} & 4.010052 & -0.341068 & 1.472444 \\ \mathrm{H} & 2.416608 & 0.302796 & 1.913019 \\ \mathrm{H} & 2.591517 & -1.409673 & 1.423836 \\ \mathrm{H} & -2.453235 & -2.333911 & -0.467426\end{array}$

Met: methyl group gauche $\mathbf{A}$

B3LYP/6-31+G(d,p) hf = -800.5933211

$\begin{array}{lrrr}\mathrm{C} & -3.443716 & 0.722461 & 0.434983 \\ \mathrm{~S} & -2.629212 & -0.641765 & -0.469315 \\ \mathrm{C} & -0.937689 & -0.572053 & 0.239871 \\ \mathrm{C} & -0.113139 & 0.632137 & -0.225248 \\ \mathrm{C} & 1.295891 & 0.738582 & 0.407251 \\ \mathrm{~N} & 1.893481 & 2.015139 & 0.026220 \\ \mathrm{C} & 2.154098 & -0.458535 & -0.011561 \\ \mathrm{O} & 2.127660 & -1.465510 & 0.897695 \\ \mathrm{H} & 2.765313 & 2.171716 & 0.525491 \\ \mathrm{H} & 2.118832 & 2.010325 & -0.966662 \\ \mathrm{H} & 1.196625 & 0.716638 & 1.497765 \\ \mathrm{O} & 2.791356 & -0.529260 & -1.041981 \\ \mathrm{H} & -0.014378 & 0.610512 & -1.317148 \\ \mathrm{H} & -0.621581 & 1.566334 & 0.031408 \\ \mathrm{H} & -0.475603 & -1.514416 & -0.068845 \\ \mathrm{H} & -1.014670 & -0.599464 & 1.333187 \\ \mathrm{H} & -4.489089 & 0.724331 & 0.117367 \\ \mathrm{H} & -3.406179 & 0.554077 & 1.515295 \\ \mathrm{H} & -3.006095 & 1.694428 & 0.194156 \\ \mathrm{H} & 2.675054 & -2.189593 & 0.545997\end{array}$

Fm-Met: N-H...S bond, methyl group equatorial B3LYP/6-31+G(d,p) hf $=-913.9420965$

$\begin{array}{lrrr}\mathrm{C} & 3.530331 & -0.230197 & -1.208796 \\ \mathrm{~S} & 2.500697 & -0.669874 & 0.234832 \\ \mathrm{C} & 1.600775 & 0.924880 & 0.491475 \\ \mathrm{C} & 0.366814 & 0.748795 & 1.393034 \\ \mathrm{C} & -0.915868 & 0.227154 & 0.727341 \\ \mathrm{~N} & -0.711401 & -1.090044 & 0.104862 \\ \mathrm{C} & -1.522990 & 1.252163 & -0.269368 \\ \mathrm{C} & -1.717211 & -1.945715 & -0.154603 \\ \mathrm{O} & -2.694542 & 0.900823 & -0.808025 \\ \mathrm{H} & 4.113114 & -1.117002 & -1.467061 \\ \mathrm{H} & 2.910646 & 0.054099 & -2.063047 \\ \mathrm{H} & 4.216367 & 0.583371 & -0.959584 \\ \mathrm{H} & 2.293042 & 1.629843 & 0.960421 \\ \mathrm{H} & 1.311197 & 1.333801 & -0.479046 \\ \mathrm{H} & 0.121689 & 1.730246 & 1.808991 \\ \mathrm{H} & 0.609295 & 0.097756 & 2.241868 \\ \mathrm{H} & -1.673421 & 0.089572 & 1.511376 \\ \mathrm{H} & 0.249895 & -1.373391 & -0.086202 \\ \mathrm{O} & -0.996878 & 2.315173 & -0.519534 \\ \mathrm{H} & -2.985095 & 0.006414 & -0.491511 \\ \mathrm{H} & -1.385150 & -2.935403 & -0.503182 \\ \mathrm{O} & -2.916583 & -1.667683 & -0.027300\end{array}$

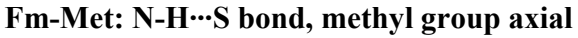
B3LYP/6-31+G(d,p) hf $=-913.942358$

$\begin{array}{lrrr}\text { N } & 0.597441 & 1.081389 & -0.053349 \\ \mathrm{C} & 0.792461 & -0.174861 & 0.686868 \\ \mathrm{C} & 1.684413 & -1.182822 & -0.088456 \\ \mathrm{O} & 2.901150 & -0.736847 & -0.414768 \\ \mathrm{C} & 1.551700 & 2.021773 & -0.177370 \\ \mathrm{C} & -0.548520 & -0.787427 & 1.119765 \\ \mathrm{C} & -1.546078 & -1.171374 & 0.013850 \\ \mathrm{~S} & -2.436597 & 0.210398 & -0.824405 \\ \mathrm{C} & -3.583599 & 0.745919 & 0.495037 \\ \mathrm{H} & -0.328336 & 1.247042 & -0.449011 \\ \mathrm{H} & 1.356982 & 0.080150 & 1.594739 \\ \mathrm{O} & 1.325750 & -2.311451 & -0.346700 \\ \mathrm{H} & 3.035423 & 0.200212 & -0.117907 \\ \mathrm{O} & 2.721805 & 1.879526 & 0.200340 \\ \mathrm{H} & 1.206336 & 2.950035 & -0.657454 \\ \mathrm{H} & -0.306924 & -1.704123 & 1.667685 \\ \mathrm{H} & -1.018650 & -0.106767 & 1.839038 \\ \mathrm{H} & -2.306273 & -1.841476 & 0.427722 \\ \mathrm{H} & -1.038871 & -1.719124 & -0.783156 \\ \mathrm{H} & -4.191848 & 1.549640 & 0.074170 \\ \mathrm{H} & -4.240891 & -0.077482 & 0.787249 \\ \mathrm{H} & -3.055390 & 1.128731 & 1.371712\end{array}$

Fm-Met: N-H -.S bond, methyl group equatorial B3LYP/6-31G(d) hf = -913.8969794

$\begin{array}{lrrr}\mathrm{C} & 3.554520 & -0.209761 & -1.188177 \\ \mathrm{~S} & 2.495544 & -0.691320 & 0.220409 \\ \mathrm{C} & 1.601343 & 0.900586 & 0.509335 \\ \mathrm{C} & 0.364781 & 0.711432 & 1.405102 \\ \mathrm{C} & -0.919046 & 0.214658 & 0.723502 \\ \mathrm{~N} & -0.733504 & -1.095725 & 0.084307 \\ \mathrm{C} & -1.500856 & 1.263229 & -0.263027 \\ \mathrm{C} & -1.757463 & -1.928496 & -0.178640 \\ \mathrm{O} & -2.682415 & 0.943208 & -0.798836 \\ \mathrm{H} & 4.130144 & -1.093452 & -1.474640 \\ \mathrm{H} & 2.952965 & 0.118386 & -2.040491 \\ \mathrm{H} & 4.247906 & 0.584505 & -0.897483 \\ \mathrm{H} & 2.295816 & 1.594107 & 0.993061 \\ \mathrm{H} & 1.309846 & 1.331711 & -0.450933 \\ \mathrm{H} & 0.124333 & 1.687152 & 1.838218 \\ \mathrm{H} & 0.602125 & 0.042929 & 2.242051 \\ \mathrm{H} & -1.685077 & 0.074055 & 1.498885 \\ \mathrm{H} & 0.219880 & -1.384044 & -0.130263 \\ \mathrm{O} & -0.947043 & 2.311388 & -0.510076 \\ \mathrm{H} & -2.985808 & 0.053764 & -0.476246 \\ \mathrm{H} & -1.441321 & -2.918867 & -0.544399 \\ \mathrm{O} & -2.948624 & -1.638212 & -0.031466\end{array}$




\section{Efforts Toward Developing Direct Probes of Protein Dynamics}

Matthew E. Cremeens, ${ }^{\dagger}$ Hiroshi Fujisaki, ${ }^{\ddagger}$ Yong Zhang, ${ }^{\ddagger}$ Jörg Zimmermann, ${ }^{\dagger}$ Laura B. Sagle ${ }^{\dagger}$ Shigeo Matsuda, ${ }^{\dagger}$ Philip E. Dawson, ${ }^{\dagger}$ John E. Straub, ${ }^{\ddagger}$ and Floyd E. Romesberg ${ }^{\dagger *}$

${ }^{\dagger}$ Department of Chemistry, The Scripps Research Institute, 10550 North Torrey Pines Road, La Jolla, CA 92037 and Department of Chemistry, Boston University, 590 Commonwealth Avenue, Boston, MA 02215

Fm-Met: N-H'..S bond, methyl group axial

$\begin{array}{lrrr}\text { B3LYP/6-31G(d) hf }= & -913.8972858 \\ \text { N } & 0.608949 & 1.086186 & -0.064020 \\ \text { C } & 0.793338 & -0.165229 & 0.684557 \\ \text { C } & 1.668164 & -1.190004 & -0.087792 \\ \text { O } & 2.891907 & -0.762513 & -0.411078 \\ \text { C } & 1.575993 & 2.012969 & -0.188800 \\ \text { C } & -0.549086 & -0.764547 & 1.129760 \\ \text { C } & -1.546054 & -1.164759 & 0.028832 \\ \text { S } & -2.441339 & 0.203568 & -0.827341 \\ \text { C } & -3.573029 & 0.764830 & 0.494432 \\ \text { H } & -0.309865 & 1.253249 & -0.471598 \\ \text { H } & 1.366305 & 0.094948 & 1.585854 \\ \text { O } & 1.290182 & -2.310680 & -0.347745 \\ \text { H } & 3.030650 & 0.173063 & -0.106543 \\ \text { O } & 2.738856 & 1.866346 & 0.200169 \\ \text { H } & 1.239676 & 2.941928 & -0.677369 \\ \text { H } & -0.308575 & -1.674959 & 1.689470 \\ \text { H } & -1.019075 & -0.073493 & 1.839791 \\ \text { H } & -2.303980 & -1.833326 & 0.450440 \\ \text { H } & -1.031590 & -1.719507 & -0.758557 \\ \text { H } & -4.181423 & 1.567114 & 0.069230 \\ \text { H } & -4.232709 & -0.050255 & 0.806399 \\ \text { H } & -3.034156 & 1.156078 & 1.361774\end{array}$

Fm-Met: $\mathrm{CO}_{2}-\mathrm{H} \cdots \mathrm{S}$ bond, methyl group equatorial B3LYP/6-31G(d) hf $=-913.8829055$

$\begin{array}{lrrr}\text { C } & 3.565626 & -0.357007 & -0.220539 \\ \mathrm{~S} & 1.801368 & -0.827168 & -0.320820 \\ \mathrm{C} & 1.209383 & -0.032868 & 1.238870 \\ \mathrm{C} & -0.303737 & -0.157143 & 1.455970 \\ \mathrm{C} & -1.242297 & 0.371629 & 0.338175 \\ \mathrm{~N} & -1.338072 & -0.551099 & -0.798923 \\ \mathrm{C} & -0.853499 & 1.775516 & -0.146665 \\ \mathrm{C} & -2.057732 & -1.708934 & -0.712060 \\ \mathrm{O} & 0.160173 & 1.846175 & -1.044801 \\ \mathrm{H} & 4.053798 & -0.745200 & -1.117826 \\ \mathrm{H} & 3.684512 & 0.729882 & -0.191245 \\ \mathrm{H} & 4.034607 & -0.805742 & 0.659783 \\ \mathrm{H} & 1.728308 & -0.508396 & 2.077491 \\ \mathrm{H} & 1.513349 & 1.019945 & 1.210324 \\ \mathrm{H} & -0.539963 & 0.401635 & 2.370097 \\ \mathrm{H} & -0.585898 & -1.197468 & 1.638169 \\ \mathrm{H} & -2.237066 & 0.469539 & 0.780353 \\ \mathrm{H} & -1.089962 & -0.220266 & -1.722004 \\ \mathrm{O} & -1.408645 & 2.771895 & 0.242375 \\ \mathrm{H} & 0.654094 & 0.992591 & -1.104621 \\ \mathrm{H} & -2.129606 & -2.231797 & -1.685169 \\ \mathrm{O} & -2.557530 & -2.138008 & 0.313391\end{array}$

Fm-Met: $\mathrm{CO}_{2}-\mathrm{H} \cdots \mathrm{S}$ bond, methyl group axial B3LYP/6-31G(d) hf $=-913.8811383$

$\begin{array}{lrrr}\mathrm{C} & -2.798440 & 0.552447 & -0.247068 \\ \mathrm{~S} & -1.958632 & -1.065054 & -0.362303 \\ \mathrm{C} & -0.984071 & -1.101779 & 1.200092 \\ \mathrm{C} & 0.051166 & 0.008499 & 1.436950 \\ \mathrm{C} & 1.148137 & 0.261559 & 0.366207 \\ \mathrm{~N} & 0.697684 & 1.102452 & -0.751611 \\ \mathrm{C} & 1.766542 & -1.035313 & -0.171967 \\ \mathrm{C} & 0.547736 & 2.450833 & -0.607654 \\ \mathrm{O} & 1.080726 & -1.660376 & -1.161303 \\ \mathrm{H} & -3.464875 & 0.620320 & -1.110680 \\ \mathrm{H} & -3.400223 & 0.602642 & 0.664892 \\ \mathrm{H} & -2.089553 & 1.382325 & -0.272583 \\ \mathrm{H} & -1.688605 & -1.112491 & 2.038609 \\ \mathrm{H} & -0.502890 & -2.085854 & 1.179323 \\ \mathrm{H} & 0.572078 & -0.250761 & 2.367905 \\ \mathrm{H} & -0.437596 & 0.969368 & 1.619485 \\ \mathrm{H} & 1.957164 & 0.793325 & 0.873650 \\ \mathrm{H} & 0.763611 & 0.736550 & -1.692386 \\ \mathrm{O} & 2.802891 & -1.484272 & 0.247240 \\ \mathrm{H} & 0.161606 & -1.310702 & -1.233397 \\ \mathrm{H} & 0.354248 & 2.957064 & -1.573767 \\ \mathrm{O} & 0.596751 & 3.045202 & 0.456275\end{array}$

Fm-Met: No X-H...S bond, methyl group anti B3LYP/6-31G(d) hf $=-913.8937426$

$\begin{array}{lrrr}\mathrm{C} & -3.183019 & -1.279911 & -0.008000 \\ \mathrm{~N} & -1.955661 & -1.112754 & -0.543925 \\ \mathrm{C} & -0.931805 & -0.240563 & 0.055166 \\ \mathrm{C} & -1.251818 & 1.251484 & -0.229454 \\ \mathrm{C} & 0.453599 & -0.653915 & -0.451780 \\ \mathrm{O} & -2.385304 & 1.701696 & 0.321950 \\ \mathrm{C} & 1.594919 & 0.006030 & 0.327085 \\ \mathrm{~S} & 3.201714 & -0.667898 & -0.255485 \\ \mathrm{C} & 4.335517 & 0.395934 & 0.702568 \\ \mathrm{O} & -3.605046 & -0.647680 & 0.961018 \\ \mathrm{H} & -3.789361 & -2.048138 & -0.515330 \\ \mathrm{H} & -1.712289 & -1.628416 & -1.380083 \\ \mathrm{H} & -0.995913 & -0.389870 & 1.141236 \\ \mathrm{O} & -0.530365 & 1.963527 & -0.888554 \\ \mathrm{H} & 0.542294 & -0.390241 & -1.511672 \\ \mathrm{H} & 0.534962 & -1.744834 & -0.362800 \\ \mathrm{H} & 1.577182 & 1.086253 & 0.164450 \\ \mathrm{H} & 1.492361 & -0.193172 & 1.401184 \\ \mathrm{H} & 5.353117 & 0.100050 & 0.434821 \\ \mathrm{H} & 4.199630 & 0.254764 & 1.779284 \\ \mathrm{H} & 4.195518 & 1.450669 & 0.447555 \\ \mathrm{H} & -2.873935 & 0.963903 & 0.767766\end{array}$

Met $\cdot \mathrm{H}_{2} \mathrm{O}: \mathrm{HO}-\mathrm{H} \cdot \cdots \mathrm{S}$ bond, methyl group anti B3LYP/6-31G(d) hf $=-876.9654518$

$\begin{array}{lrrr}\text { H } & -3.441058 & 0.866667 & -1.333542 \\ \mathrm{~N} & -2.456558 & 1.125159 & -1.292928 \\ \mathrm{C} & -1.659661 & -0.012377 & -0.805171 \\ \mathrm{C} & -2.178493 & -0.496009 & 0.551700 \\ \mathrm{C} & -0.182216 & 0.391046 & -0.761379 \\ \mathrm{O} & -3.395196 & -1.091493 & 0.419197 \\ \mathrm{C} & 0.758141 & -0.756031 & -0.379869 \\ \mathrm{~S} & 2.504983 & -0.182011 & -0.470614 \\ \mathrm{C} & 3.350521 & -1.612520 & 0.287099 \\ \mathrm{H} & 2.017381 & 1.894821 & 0.982771 \\ \mathrm{O} & 1.568569 & 2.754222 & 1.077159 \\ \mathrm{H} & -2.380638 & 1.899608 & -0.633286 \\ \mathrm{H} & -1.802789 & -0.832019 & -1.520592 \\ \mathrm{O} & -1.651704 & -0.340566 & 1.631872 \\ \mathrm{H} & -0.045695 & 1.217769 & -0.054094 \\ \mathrm{H} & 0.068261 & 0.769024 & -1.759123 \\ \mathrm{H} & -3.689505 & -1.311614 & 1.323390 \\ \mathrm{H} & 0.555944 & -1.086301 & 0.642467 \\ \mathrm{H} & 0.636447 & -1.609279 & -1.058514 \\ \mathrm{H} & 4.418772 & -1.381927 & 0.307021 \\ \mathrm{H} & 3.003490 & -1.779142 & 1.311049 \\ \mathrm{H} & 3.196795 & -2.518311 & -0.307015 \\ \mathrm{H} & 1.875667 & 3.244826 & 0.299680\end{array}$




\title{
Efforts Toward Developing Direct Probes of Protein Dynamics
}

\author{
Matthew E. Cremeens, ${ }^{\dagger}$ Hiroshi Fujisaki, ${ }^{\ddagger}$ Yong Zhang, ${ }^{\ddagger}$ Jörg Zimmermann, ${ }^{\dagger}$ Laura B. Sagle ${ }^{\dagger}$ \\ Shigeo Matsuda, ${ }^{\dagger}$ Philip E. Dawson, ${ }^{\dagger}$ John E. Straub, ${ }^{\ddagger}$ and Floyd E. Romesberg ${ }^{\dagger *}$ \\ ${ }^{\dagger}$ Department of Chemistry, The Scripps Research Institute, 10550 North Torrey Pines Road, La Jolla, CA \\ 92037 and Department of Chemistry, Boston University, 590 Commonwealth Avenue, Boston, MA 02215
}

Frequencies. Note that anharmonic calculations are not accurate for low frequency modes of non-rigid molecules, consequently numerical errors for such modes (especially $v<\sim 300$ $\mathrm{cm}^{-1}$ ) incurred during computation were ignored to save computational time since only the stretching modes were of interest and upon resubmitting a job, the error(s) did not arise.

Harmonic \& Anharmonic v's of Fm-Met- $d_{1}, \mathrm{~N}-\mathrm{H} \cdot \cdots \cdot \mathrm{S}$ bond, equatorial methyl: $\mathrm{B} 3 \mathrm{LYP} / 6-31+\mathrm{G}(\mathrm{d}, \mathrm{p})$ Harm $=$ harmonic, Anh $=$ anharmonic, Anh-FR = anharmonic $v$ with Fermi resonance removed. anti C-D gauche C-D Harm Anh Anh-FR Harm Anh Anh-FR Harm Anh Anh-FR

2(1) $3450.6 \quad 3261.5$

2(1) $\quad 3319.7 \quad 3029.9$

$\begin{array}{lll}4(1) & 3140.4 & 2980.4 \\ & 3133.3 & 2962 .\end{array}$ $3450.63257 .7 \quad$ Anh-FR Harm Anh 3450.63384 .5 3319.73028 .5 3150.22999 .1 3135.02978 .2 $3110.62964 .2 \quad 3110.62964 .2$ $3080.72949 .5-3089.92954 .8$ $\begin{array}{llll}3072.6 & 2938.7 & 3072.7 & 2947.4\end{array}$ 3054.32932 .8 3047.02861 .0

$\begin{array}{lll}9(1) & 3047.0 & 2860.6 \\ 10(1) & 3034.4 & 2895.8\end{array}$

11(1) 2291.92221 .32221 .8

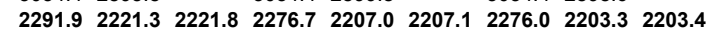

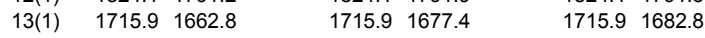

$\begin{array}{llllll}14(1) & 1555.9 & 1513.4 & 1555.9 & 1509.4\end{array}$

15(1) $\quad 1498.21286 .5 \quad 1497.91452 .8$

16(1) $\quad 1479.11434 .8$

$16(1)$

17(1) $\quad 1469.01432 .0$

18(1) $\quad 1430.61390 .7$

19(1) $\quad 1406.2 \quad 1374.1$

20(1) $\quad 1395.4 \quad 1322.2$

21(1) $\quad 1372.3 \quad 1330.5$

22(1) $\quad 1345.8 \quad 1313.4$

23(1) $\quad 1326.2 \quad 1009.1$

24(1) $\quad 1287.2 \quad 1252.0$

25(1) $\quad 1280.1 \quad 1250.4$

26(1) $\quad 1265.6 \quad 1229.2$

27(1) $\quad 1243.5 \quad 1197.6$

28(1) $\quad 1232.9 \quad 1162.3$

29(1) $\quad 1166.5 \quad 934.1$

30(1) $\quad 1115.6 \quad 1080.3$

31(1) $\quad 1062.7 \quad 1013.6$

32(1) $\quad 1024.3 \quad 1004.4$

$\begin{array}{lll}33(1) & 1013.2 & 987.4\end{array}$

34(1) $\quad 960.0 \quad 935.3$

$35(1) \quad 907.0 \quad 822.3$

36(1) $\quad 894.6 \quad 841.2$

$\begin{array}{lll}37(1) & 888.0 & 831.2\end{array}$

$\begin{array}{lll}38(1) & 867.1 & 832.0\end{array}$

$\begin{array}{lll}39(1) & 828.7 \quad 803.6\end{array}$

40(1) $\quad 788.3 \quad 772.5$

$41(1) \quad 730.5 \quad 701.8$

42(1) $\quad 697.2 \quad 673.6$

43(1) $\quad 689.1-1189.2$

$\begin{array}{lll}44(1) & 634.1 & 621.8 \\ 45(1) & 614.8 & 550.5\end{array}$

$\begin{array}{lll}45(1) & 614.8 & 550.5\end{array}$

$\begin{array}{lll}46(1) \quad 542.5 & 483.8\end{array}$

$\begin{array}{lll}47(1) \quad 430.0 & 373.2\end{array}$

$\begin{array}{llll}48(1) & 387.3 \quad 381.7\end{array}$

$\begin{array}{lll}49(1) \quad 317.0 & 294.9\end{array}$

$\begin{array}{lll}50(1) \quad 289.7 & 30.6\end{array}$

$\begin{array}{lll}51(1) & 259.7 & 247.7\end{array}$

$\begin{array}{lll}52(1) \quad 234.9 & 217.0\end{array}$

$53(1) \quad 211.3 \quad-115.2$

$\begin{array}{lrr}54(1) & 184.4 & 80.5 \\ 55(1) & 147.3 & 127.6\end{array}$

$\begin{array}{lll}55(1) & 147.3 \quad 127.6\end{array}$

$\begin{array}{lll}56(1) & 130.4 & 100.8\end{array}$

$\begin{array}{lll}57(1) & 114.5 \quad 104.1\end{array}$

$\begin{array}{lll}58(1) & 82.1 & 79.3\end{array}$

$\begin{array}{lrr}59(1) & 52.9 & -117.1 \\ 60(1) & 44.4 & 35.9\end{array}$

Frequencies -- 2291.9

Red. masses -- 2.2494

Frc consts -- 6.9617

IR Inten -- 5.198

rel. Int. $\quad 0.53$

3450.63384 .5

3319.73151 .0

3135.22977 .0

3110.62964 .5

3089.32957 .2

3072.72948 .2

3054.32932 .4

3054.32932 .4
3047.02860 .6

1498.01451 .5

1406.21381 .8

1395.41362 .7

$\begin{array}{lllll}1372.3 & 1329.8 & 1372.3 & 1331.4\end{array}$

$\begin{array}{llll}1345.8 & 1309.7 & 1345.7 & 1311.5\end{array}$

$\begin{array}{lllll}1325.3 & 1293.7 & 1325.2 & 1293.3\end{array}$

$1298.11264 .9 \quad 1297.71241 .0$

$1280.11243 .4 \quad 1282.21247 .9$

$\begin{array}{lllll}1273.5 & 1247.1 & 1273.5 & 1242.4\end{array}$

$1243.51212 .9 \quad 1243.61216 .8$

$\begin{array}{llll}1233.1 & 1186.2 & 1233.1 & 1194.8\end{array}$

$\begin{array}{llll}1166.6 & 1138.8 & 1166.61135 .3\end{array}$

$1115.8 \quad 1075.8 \quad 1116.11083 .6$

$1063.8 \quad 619.2 \quad 1063.51035 .4$

$1024.41000 .1 \quad 1024.91002 .0$

$\begin{array}{llll}1015.4 & 980.0 & 1017.2 & 992.3\end{array}$

$\begin{array}{llll}956.9 & 934.2 & 950.5 & 936.4\end{array}$

$\begin{array}{llll}907.0 & 883.2 & 908.3 & 885.3\end{array}$

$\begin{array}{llll}895.2 & 860.9 & 896.0 & 872.9\end{array}$

$\begin{array}{llll}884.0 & 848.3 & 887.3 & 858.0\end{array}$

$\begin{array}{llll}860.6 & 826.3 & 859.4 & 838.6\end{array}$

$\begin{array}{llll}800.8 & 787.3 & 802.8 & 783.4\end{array}$

$\begin{array}{llll}788.3 & 774.6 & 788.5 & 776.5 \\ 730.3 & 731.9 & 730.5 & 719.8\end{array}$

$\begin{array}{llll}730.3 & 731.9 & 730.5 & 719.8 \\ 701.9 & 68.7 & 701.7 & 684.4\end{array}$

$\begin{array}{llll}701.9 & 684.7 & 701.7 & 684.4\end{array}$

$\begin{array}{llll}690.1 & 650.1 & 688.6 & 653.5\end{array}$

$\begin{array}{llll}653.1 & 637.7 & 653.0 & 637.6\end{array}$

$614.8 \quad 583.1$

$\begin{array}{llll}542.4 & 524.3 & 542.5 & 535.0\end{array}$

$\begin{array}{llll}429.5 & 444.7 & 429.4 & 425.9\end{array}$

$\begin{array}{llll}387.1 & 373.5 & 387.2 & 384.2\end{array}$

$\begin{array}{llll}316.7 & 342.1 & 316.7 & 309.0\end{array}$

$\begin{array}{llll}289.3 & 282.3 & 289.3 & 283.6\end{array}$

$259.5 \quad 239.1 \quad 259.2 \quad 251.9$

$\begin{array}{llll}234.6 & 239.2 & 235.0 & 229.1\end{array}$

$\begin{array}{llll}209.1 & 158.4 & 214.3 & 189.6\end{array}$

$\begin{array}{llll}185.2 & 155.5 & 187.6 & 179.2\end{array}$

$\begin{array}{llll}152.2 & 134.0 & 146.3 & 129.3\end{array}$

$\begin{array}{llll}129.9 & 129.9 & 129.9 & 129.9\end{array}$

$\begin{array}{llll}115.3 & 108.9 & 113.3 & 99.7\end{array}$

$\begin{array}{rrrr}82.0 & -68.2 & 82.0 & 81.5\end{array}$

$\begin{array}{rrrr}52.0 & 0.7 & 52.9 & 44.8 \\ 44.2 & -158.0 & 44.3 & 37.1\end{array}$

2276.7

2.2477
6.8639

8.8335

0.90

2276.0
2.2479
6.8609
9.7616

0.99 methyl: B3LYP/6-31+G(d,p) Harm = harmonic, Anh = anharmonic,

Anh-FR $=$ anharmonic $v$ with Fermi resonance removed.

\begin{tabular}{|c|c|c|c|c|c|c|c|c|c|}
\hline & anti $C-D$ & & & gauche & C-D & & gauche & C-D & \\
\hline & Harm & Anh & Anh-FR & Harm & Anh & Anh-FR & Harm & Anh & Anh-FR \\
\hline 1(1) & 3446.7 & 3264.3 & & 3446.7 & 3253.7 & & 3446.7 & 3253.2 & \\
\hline 2(1) & 3322.0 & 3042.1 & & 3322.0 & 3014.2 & & 3322.0 & 3013.7 & \\
\hline $3(1)$ & 3143.3 & 2772.3 & & 3148.8 & 2988.2 & & 3148.5 & 2991.3 & \\
\hline 4(1) & 3136.6 & 2967.7 & & 3143.2 & 2995.7 & & 3143.1 & 2996.3 & \\
\hline $5(1)$ & 3100.9 & 2924.0 & & 3100.9 & 2948.6 & & 3100.9 & 2949.5 & \\
\hline $6(1)$ & 3078.9 & 2938.8 & & 3091.1 & 2947.6 & & 3087.0 & 2947.9 & \\
\hline $7(1)$ & 3071.5 & 2895.2 & & 3071.6 & 2935.2 & & 3071.2 & 2935.4 & \\
\hline $8(1)$ & 3057.3 & 2917.0 & & 3057.3 & 2924.0 & & 3057.4 & 2925.5 & \\
\hline $9(1)$ & 3045.8 & 2858.9 & & 3045.8 & 2863.7 & & 3045.8 & 2863.8 & \\
\hline $10(1)$ & 3031.8 & 2888.4 & & 3031.8 & 2887.2 & & 3031.8 & 2886.9 & \\
\hline 11(1) & 2291.4 & 2220.6 & 2220.5 & 2273.3 & 2199.6 & 2199.6 & 2276.4 & 2197.0 & 2197.3 \\
\hline $12(1)$ & 1824.5 & 1793.2 & & 1824.5 & 1790.9 & & 1824.5 & 1791.4 & \\
\hline $13(1)$ & 1715.9 & 1662.8 & & 1715.9 & 1667.4 & & 1715.9 & 1666.8 & \\
\hline
\end{tabular}

14(1) $\quad 1554.2 \quad 1400.0$

15(1) $\quad 1476.4 \quad 1426.4$

16(1) $\quad 1473.2 \quad 575.0$

17(1) $\quad 1469.0 \quad 1419.5$

18(1) $\quad 1434.91358 .7$

19(1) $\quad 1406.4 \quad 1375.6$

20(1) $\quad 1394.8 \quad 1339.2$

21(1) $\quad 1370.91321 .1$

22(1) $\quad 1349.2 \quad 1303.1$

23(1) $\quad 1326.1 \quad 711.1$

24(1) $\quad 1287.8 \quad 1226.1$

25(1) $\quad 1282.9 \quad 1241.5$

26(1) $\quad 1266.21202 .8$

27(1) $\quad 1240.9 \quad 1114.4$

28(1) $\quad 1232.8 \quad 1169.8$

29(1) $\quad 1184.9 \quad 1070.7$

$\begin{array}{lll}30(1) & 1112.5 & 966.1\end{array}$

31(1) $\quad 1055.6 \quad 927.6$

32(1) $\quad 1024.0 \quad 894.1$

33(1) $\quad 1015.8 \quad 646.2$

34(1) $\quad 956.8 \quad 937.6$

35(1) $\quad 906.7 \quad 804.3$

$36(1) \quad 893.0 \quad 837.3$

37(1) $\quad 878.7 \quad 818.8$

38(1) $\quad 861.4 \quad 719.0$

\begin{tabular}{lll}
$39(1)$ & 807.7 & 569.1 \\
\hline $40(1)$ & 787.5 & 751.3
\end{tabular}

40(1) $\quad 787.5 \quad 751.3$

41(1) $\quad 729.4 \quad 556.9$

42(1) $\quad 709.3 \quad 564.0$

43(1) $\quad 687.9 \quad 655.2$

$\begin{array}{lll}44(1) & 619.9 & 495.1\end{array}$

45(1) $\quad 612.6 \quad 431.4$

46(1) $\quad 539.5 \quad 332.9$

47(1) $\quad 426.0 \quad 275.5$

48(1) $\quad 388.6 \quad 365.8$

$\begin{array}{lll}49(1) & 326.4 & 293.5 \\ 50(1) & 286.5 & 271.9\end{array}$

51(1) $273.6-5843.4$

52(1) $\quad 259.2 \quad-254.5$

53(1) $\quad 233.4 \quad 202.2$

54(1) $\quad 174.4 \quad 122.3$

55(1) $\quad 151.8 \quad 23.2$

56(1) $\quad 134.6 \quad 10.0$

$\begin{array}{lll}57(1) & 115.9 & -23.4\end{array}$

58(1) $\quad 82.2-336.1$

$\begin{array}{lll}59(1) & 66.4 & -503.0 \\ 60(1) & 48.2 & -908.4\end{array}$

1554.11508 .4

1477.31434 .6

1473.21429 .1

1457.41408 .0

$1434.8 \quad 1371.8$

1406.31374 .2

$1394.4 \quad 1360.3$

1370.91329 .7

$1349.0 \quad 1305.1$

$1327.0 \quad 1293.3$

1296.61257 .3

1284.91251 .1

1271.81233 .6

$1241.0 \quad 1208.4$

1232.31200 .7

1185.11157 .6

1112.51083 .2

1055.91028 .6

1027.51003 .9

1020.11000 .1

$952.5 \quad 920.2$

$901.1 \quad 878.9$

892.3848 .7

$\begin{array}{ll}864.5 & 850.9\end{array}$

$\begin{array}{ll}858.9 & 837.8\end{array}$

$\begin{array}{ll}794.6 & 781.7\end{array}$

$787.4 \quad 774.8$

$\begin{array}{ll}730.6 & 715.3\end{array}$

$710.2 \quad 652.1$

$694.3 \quad 674.2$

$629.8 \quad 615.5$

$\begin{array}{ll}612.7 & 598.1\end{array}$

$539.5 \quad 533.3$

$426.1 \quad 420.8$

$388.7 \quad 382.1$

$326.9 \quad 315.7$

$287.5 \quad 275.0$

$273.6 \quad 258.6$

$258.8 \quad 248.3$

$233.4 \quad 228.4$

$172.7 \quad 162.0$

$162.7 \quad 68.7$

$129.6 \quad 83.3$

$114.9 \quad 89.3$

$82.3 \quad 65.6$

$\begin{array}{ll}65.8 & 44.7 \\ 47.9 & 32.8\end{array}$

1554.21510 .1

1475.41438 .1

1473.81431 .1

$1451.2 \quad 1403.4$

$1434.9 \quad 1371.9$

1406.41371 .7

1394.61363 .4

1370.91332 .1

1349.21304 .8

1327.11294 .0

1299.71266 .4

1287.01251 .7

1273.21239 .6

1240.91210 .2

$1232.0 \quad 1202.3$

1184.81157 .6

1112.51084 .9

1055.71031 .1

1028.51008 .1

$1020.3 \quad 990.1$

$950.7 \quad 930.0$

$899.2 \quad 878.1$

$892.4 \quad 850.0$

$861.6 \quad 847.4$

$855.9 \quad 842.4$

$801.0 \quad 775.5$

$787.6 \quad 775.6$

$731.0 \quad 715.8$

$709.2 \quad 649.5$

$695.6 \quad 678.5$

$629.7 \quad 616.8$

$612.5 \quad 600.7$

$539.4 \quad 535.2$

$425.7 \quad 418.2$

$388.5 \quad 405.6$

$326.7 \quad 326.7$

$286.1 \quad 277.4$

$274.5 \quad 261.5$

$259.6 \quad 253.1$

$233.5 \quad 229.5$

$176.7 \quad 165.5$

$151.2 \quad 73.1$

$135.2 \quad 106.1$ 


\title{
Efforts Toward Developing Direct Probes of Protein Dynamics
}

\author{
Matthew E. Cremeens, ${ }^{\dagger}$ Hiroshi Fujisaki, ${ }^{\ddagger}$ Yong Zhang, ${ }^{\ddagger}$ Jörg Zimmermann, ${ }^{\dagger}$ Laura B. Sagle ${ }^{\dagger}$ \\ Shigeo Matsuda, ${ }^{\dagger}$ Philip E. Dawson, ${ }^{\dagger}$ John E. Straub, ${ }^{\ddagger}$ and Floyd E. Romesberg ${ }^{\dagger *}$ \\ ${ }^{\dagger}$ Department of Chemistry, The Scripps Research Institute, 10550 North Torrey Pines Road, La Jolla, CA \\ 92037 and Department of Chemistry, Boston University, 590 Commonwealth Avenue, Boston, MA 02215
}

Harmonic \& Anharmonic $v$ 's of Fm-Met- $d_{3}, N-H \cdots \cdot$. bond: B3LYP/6-31+G(d,p) Harm = harmonic, Anh = anharmonic, Anh-FR $=$ anharmonic $v$ with Fermi resonance removed.

\begin{tabular}{lcll}
\multicolumn{5}{c}{ Equat. } & \\
& Harm & Anh & Anh-FR \\
$1(1)$ & 3450.6 & 3257.5 & \\
$2(1)$ & 3319.7 & 3004.0 & \\
$3(1)$ & 3135.1 & 2974.6 & \\
$4(1)$ & 3110.6 & 2968.2 & \\
$5(1)$ & 3072.7 & 2948.7 & \\
$6(1)$ & 3054.3 & 2933.2 & \\
$7(1)$ & 3047.0 & 2861.2 & \\
$8(1)$ & 3034.4 & 2896.5 & \\
$\mathbf{9 ( 1 )}$ & $\mathbf{2 3 3 8 . 1}$ & $\mathbf{2 2 4 7 . 4}$ & $\mathbf{2 2 4 7 . 4}$ \\
$\mathbf{1 0 ( 1 )}$ & $\mathbf{2 3 2 9 . 8}$ & $\mathbf{2 2 3 2 . 3}$ & $\mathbf{2 2 3 2 . 3}$ \\
$\mathbf{1 1 ( 1 )}$ & $\mathbf{2 1 8 6 . 0}$ & $\mathbf{2 1 5 4 . 2}$ & $\mathbf{2 1 5 4 . 1}$ \\
$1(1)$ & 1824.1 & 1789.9 &
\end{tabular}

\begin{tabular}{llll} 
& \multicolumn{3}{c}{ Axial } \\
& Harm & Anh & Anh-FR \\
1(1) & 3446.7 & 3253.5 & \\
$2(1)$ & 3322.0 & 3013.4 & \\
$3(1)$ & 3143.2 & 2996.2 & \\
$4(1)$ & 3100.9 & 2949.7 & \\
$5(1)$ & 3071.6 & 2931.3 & \\
$6(1)$ & 3057.4 & 2827.3 & \\
$7(1)$ & 3045.8 & 2860.8 & \\
$8(1)$ & 3031.8 & 2697.0 & \\
$\mathbf{9 ( 1 )}$ & $\mathbf{2 3 3 5 . 9}$ & $\mathbf{2 2 4 9 . 3}$ & $\mathbf{2 2 4 9 . 4}$ \\
$\mathbf{1 0 ( 1 )}$ & $\mathbf{2 3 2 7 . 9}$ & $\mathbf{2 2 3 8 . 8}$ & $\mathbf{2 2 3 8 . 9}$ \\
$\mathbf{1 1 ( 1 )}$ & $\mathbf{2 1 8 6 . 2}$ & $\mathbf{2 1 5 8 . 3}$ & $\mathbf{2 1 5 8 . 3}$
\end{tabular}

12(1) $\quad 1824.1 \quad 1789.9$

13(1) $\quad 1715.9 \quad 1680.2$

14(1) $\quad 1555.81512 .0$

15(1) $\quad 1497.8 \quad 1451.7$

$\begin{array}{lll}16(1) & 1479.1 & 1437.7 \\ 17(1) & 1430.6 & 1398.5\end{array}$

18(1) $\quad 1406.2 \quad 1383.0$

19(1) $\quad 1395.3 \quad 1361.6$

20(1) $\quad 1372.3 \quad 1329.2$

21(1) $\quad 1345.6 \quad 1307.0$

22(1) $\quad 1324.1 \quad 1286.3$

23(1) $\quad 1282.9 \quad 1246.9$

24(1) $\quad 1243.9 \quad 1214.5$

25(1) $\quad 1233.2 \quad 1194.7$

26(1) $\quad 1166.6 \quad 1135.2$

27(1) $\quad 1115.6 \quad 1081.3$

28(1) $\quad 1077.1 \quad 1008.6$

29(1) $\quad 1065.2 \quad 1156.7$

30(1) $\quad 1062.6 \quad 1035.9$

31(1) $\quad 1043.5 \quad 1023.4$

32(1) $\quad 1024.2 \quad 996.9$

33(1) $\quad 1012.2 \quad 981.9$

34(1) $\quad 908.2 \quad 884.5$

35(1) $\quad 895.8 \quad 875.0$

36(1) $\quad 888.1 \quad 859.7$

$37(1) \quad 864.0 \quad 837.5$

38(1) $\quad 789.4 \quad 773.0$

39(1) $\quad 772.5 \quad 656.6$

40(1) $\quad 742.3 \quad 695.8$

41(1) $\quad 729.4 \quad 710.1$

42(1) $\quad 688.2 \quad 659.8$

43(1) $\quad 684.9 \quad 660.3$

44(1) $\quad 633.0 \quad 591.9$

45(1) $\quad 614.5 \quad 600.7$

46(1) $\quad 542.4 \quad 533.5$

$47(1) \quad 428.4 \quad 429.7$

48(1) $\quad 386.9 \quad 380.1$

49(1) $\quad 316.1 \quad 313.6$

$\begin{array}{lll}50(1) \quad 287.7 & 281.7\end{array}$

$51(1) \quad 258.3 \quad 252.5$

$52(1) \quad 234.0 \quad 225.5$

53(1) $\quad 206.5 \quad 178.4$

54(1) $\quad 180.6 \quad 145.2$

55(1) $\quad 134.7 \quad 172.2$

56(1) $\quad 129.4 \quad 137.3$

57(1) $\quad 103.5 \quad 1327.5$

$\begin{array}{llr}58(1) & 81.7 & 77.5\end{array}$

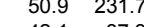

Frequencies -- $2186.0 \quad 2329.82338 .1$ Red. masses -- 2.10372 .38732 .3806

Frc consts -- $5.923 \quad 7.6344 \quad 7.6679$

IR Inten $\quad--14.882 \quad 3.8228 \quad 1.9332$

$\begin{array}{lrr}\text { rel. Int. } \quad 1.00 & 0.26 \quad 0.13\end{array}$
Harmonic \& Anharmonic v's of Met-d $\boldsymbol{d}_{3}$ : B3LYP/6-31+G(d,p)

Harm $=$ harmonic, Anh $=$ anharmonic, Anh-FR $=$ anharmonic $v$ with Fermi resonance removed.

\begin{tabular}{|c|c|c|c|c|c|c|c|c|c|}
\hline & \multicolumn{2}{|c|}{ Anti methyl } & \multicolumn{4}{|c|}{ Gauche B methyl } & \multicolumn{3}{|c|}{ Gauche A methyl } \\
\hline & Harm & Anh & Anh-FR & २ Harm & Anh & Anh-FR & Harm & Anh & Anh-FR \\
\hline 1(1) & 3735.5 & 3535.6 & & 3734.6 & 3540.2 & & 3736.9 & 3532.6 & \\
\hline 2(1) & 3588.8 & 3417.2 & & 3588.6 & 3414.6 & & 3585.8 & 3413.8 & \\
\hline $3(1)$ & 3501.1 & 3350.5 & & 3499.7 & 3347.2 & & 3499.9 & 3348.8 & \\
\hline $4(1)$ & 3112.9 & 2955.5 & & 3120.2 & 2966.0 & & 3121.5 & 2962.7 & \\
\hline $5(1)$ & 3087.8 & 2929.5 & & 3097.7 & 2943.7 & & 3101.9 & 2944.5 & \\
\hline $6(1)$ & 3081.4 & 2936.1 & & 3084.3 & 2938.7 & & 3078.5 & 2931.1 & \\
\hline $7(1)$ & 3051.8 & 2928.4 & & 3054.5 & 2930.7 & & 3057.8 & 2931.5 & \\
\hline $8(1)$ & 3040.9 & 2923.5 & & 3049.3 & 2927.1 & & 3048.7 & 2918.8 & \\
\hline $9(1)$ & 2331.2 & 2248.2 & 2248.3 & 2332.6 & 2245.0 & 2245.1 & 2331.6 & 2247.6 & 2247.6 \\
\hline 10(1) & 2317.7 & 2230.9 & 2230.9 & 2323.7 & 2236.9 & 2236.9 & 2322.4 & 2233.6 & 2233.6 \\
\hline 11(1) & 2179.8 & 2155.8 & 2155.7 & 2183.9 & 2151.7 & 2151.7 & 2182.6 & 2154.3 & $\begin{array}{l}32154.2 \\
\end{array}$ \\
\hline $12(1)$ & 1810.0 & 1818.4 & & 1807.5 & 1776.7 & & 1810.3 & 1780.6 & \\
\hline $13(1)$ & 1672.8 & 1576.8 & & 1670.3 & 1563.2 & & 1672.8 & 1580.6 & \\
\hline 14(1) & 1501.3 & 1466.8 & & 1495.0 & 1456.6 & & 1498.2 & 1455.9 & \\
\hline 15(1) & 1489.8 & 1453.7 & & 1470.7 & 1436.0 & & 1471.2 & 1436.3 & \\
\hline $16(1)$ & 1419.9 & 1386.1 & & 1418.6 & 1384.6 & & 1419.8 & 1384.2 & \\
\hline 17(1) & 1375.4 & 1333.7 & & 1373.4 & 1328.9 & & 1369.5 & 1335.3 & \\
\hline $18(1)$ & 1369.9 & 1315.7 & & 1368.0 & 1336.7 & & 1366.2 & 1318.1 & \\
\hline 19(1) & 1315.8 & 1412.1 & & 1321.0 & 1289.9 & & 1321.4 & 1281.2 & \\
\hline $20(1)$ & 1285.7 & 1257.8 & & 1290.0 & 1268.4 & & 1290.7 & 1257.8 & \\
\hline $21(1)$ & 1279.1 & 1245.0 & & 1280.1 & 1242.2 & & 1281.3 & 1248.8 & \\
\hline $22(1)$ & 1225.1 & 1204.2 & & 1224.3 & 1198.7 & & 1226.7 & 1190.8 & \\
\hline $23(1)$ & 1148.7 & 1118.9 & & 1155.6 & 1131.4 & & 1154.7 & 1125.2 & \\
\hline $24(1)$ & 1142.9 & 1109.6 & & 1145.3 & 1107.9 & & 1145.2 & 1107.0 & \\
\hline 25(1) & 1111.9 & 1086.4 & & 1113.4 & 1082.4 & & 1116.9 & 1080.7 & \\
\hline $26(1)$ & 1078.0 & 1055.6 & & 1078.3 & 1056.1 & & 1078.9 & 1054.0 & \\
\hline $27(1)$ & 1065.4 & 1042.3 & & 1066.5 & 1042.3 & & 1066.6 & 1041.6 & \\
\hline $28(1)$ & 1052.9 & 1026.0 & & 1044.4 & 1018.5 & & 1051.2 & 1021.0 & \\
\hline 29(1) & 1043.2 & 1020.4 & & 1042.1 & 1020.4 & & 1041.7 & 1018.5 & \\
\hline $30(1)$ & 1023.8 & 1002.4 & & 1025.9 & 1002.3 & & 1024.2 & 996.8 & \\
\hline $31(1)$ & 996.5 & 979.0 & & 998.0 & 979.2 & & 989.0 & 960.1 & \\
\hline $32(1)$ & 881.5 & 826.1 & & 877.0 & 818.9 & & 887.7 & 825.7 & \\
\hline $33(1)$ & 821.7 & 808.6 & & 818.8 & 803.1 & & 824.6 & 800.7 & \\
\hline $34(1)$ & 811.7 & 796.2 & & 797.3 & 778.8 & & 789.1 & 767.7 & \\
\hline $35(1)$ & 773.1 & 759.7 & & 764.1 & 750.0 & & 763.2 & 748.3 & \\
\hline $36(1)$ & 755.3 & 745.5 & & 743.7 & 726.0 & & 739.5 & 721.1 & \\
\hline $37(1)$ & 734.0 & 721.8 & & 736.4 & 724.4 & & 736.9 & 722.2 & \\
\hline $38(1)$ & 732.8 & 721.4 & & 723.2 & 717.0 & & 723.0 & 712.7 & \\
\hline $39(1)$ & 662.8 & 653.3 & & 654.7 & 642.6 & & 654.1 & 642.3 & \\
\hline $40(1)$ & 639.6 & 647.0 & & 640.8 & 630.1 & & 638.8 & 627.7 & \\
\hline $41(1)$ & 628.4 & 598.1 & & 631.1 & 622.9 & & 627.6 & 602.2 & \\
\hline $42(1)$ & 514.3 & 508.2 & & 510.0 & 504.7 & & 508.7 & 499.9 & \\
\hline $43(1)$ & 378.5 & 377.1 & & 362.6 & 355.3 & & 370.7 & 362.6 & \\
\hline 44(1) & 333.6 & 324.4 & & 351.8 & 347.8 & & 344.1 & 334.7 & \\
\hline $45(1)$ & 292.2 & 310.7 & & 293.6 & 290.8 & & 290.6 & 283.0 & \\
\hline $46(1)$ & 249.4 & 289.3 & & 251.8 & 265.8 & & 270.6 & 254.0 & \\
\hline $47(1)$ & 224.9 & 227.5 & & 244.5 & 249.5 & & 245.8 & 207.4 & \\
\hline $48(1)$ & 190.6 & 191.7 & & 206.1 & 203.8 & & 194.7 & 185.0 & \\
\hline 49(1) & 134.6 & 117.5 & & 158.9 & 155.3 & & 150.1 & 142.9 & \\
\hline $50(1)$ & 120.6 & 126.5 & & 113.1 & 91.3 & & 122.2 & 75.5 & \\
\hline 51(1) & 88.4 & 89.9 & & 100.4 & 86.9 & & 94.6 & 66.2 & \\
\hline $52(1)$ & 65.9 & 79.0 & & 65.7 & 62.4 & & 70.9 & 58.7 & \\
\hline $53(1)$ & 39.5 & 88.1 & & 34.8 & 2.6 & & 36.9 & 28.0 & \\
\hline $54(1)$ & 32.0 & 60.5 & & 26.3 & 43.9 & & 27.5 & 22.3 & \\
\hline
\end{tabular}

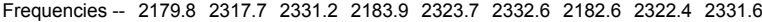
$\begin{array}{lllllllll}\text { Red. masses -- } 2.1049 & 2.3861 & 2.3776 & 2.1050 & 2.3849 & 2.3783 & 2.1053 & 2.3858 & 2.3776\end{array}$

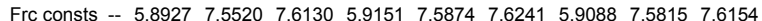

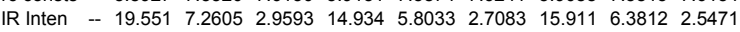

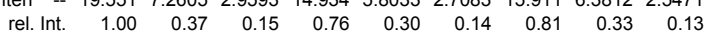




\title{
Efforts Toward Developing Direct Probes of Protein Dynamics
}

\author{
Matthew E. Cremeens, ${ }^{\dagger}$ Hiroshi Fujisaki, ${ }^{\ddagger}$ Yong Zhang, ${ }^{\ddagger}$ Jörg Zimmermann, ${ }^{\dagger}$ Laura B. Sagle ${ }^{\dagger}$ \\ Shigeo Matsuda, ${ }^{\dagger}$ Philip E. Dawson, ${ }^{\dagger}$ John E. Straub, ${ }^{\ddagger}$ and Floyd E. Romesberg ${ }^{\dagger *}$ \\ ${ }^{\dagger}$ Department of Chemistry, The Scripps Research Institute, 10550 North Torrey Pines Road, La Jolla, CA \\ 92037 and Department of Chemistry, Boston University, 590 Commonwealth Avenue, Boston, MA 02215
}

Harmonic \& Anharmonic v's of Met- $\boldsymbol{d}_{\mathbf{1}}$, anti methyl: B3LYP/6$31+\mathrm{G}(\mathrm{d}, \mathrm{p})$ Harm $=$ harmonic, Anh = anharmonic, Anh-FR = anharmonic $v$ with Fermi resonance removed.

\begin{tabular}{|c|c|c|c|c|c|c|c|c|c|}
\hline & anti $C-D$ & & & gauche & e C-D & & gauche & C-D & \\
\hline & Harm & Anh & Anh-FR & Harm & Anh & Anh-FR & Harm & Anh & Anh-FR \\
\hline 1(1) & 3735.5 & 3536.6 & & 3735.5 & 53504.0 & & 3735.5 & 3536.5 & \\
\hline 2(1) & 3588.8 & 3417.1 & & 3588.8 & 3417.1 & & 3588.8 & 3417.4 & \\
\hline $3(1)$ & 3501.1 & 3350.8 & & 3501.1 & 3350.6 & & 3501.1 & 3350.8 & \\
\hline 4(1) & 3123.2 & 2964.3 & & 3142.0 & 2987.7 & & 3141.7 & 2989.6 & \\
\hline $5(1)$ & 3112.5 & 2956.5 & & 3112.9 & 2957.6 & & 3112.9 & 2957.7 & \\
\hline $6(1)$ & 3087.6 & 2929.5 & & 3088.2 & 2930.9 & & 3088.2 & 2930.9 & \\
\hline 7(1) & 3081.4 & 2935.6 & & 3081.4 & 2936.7 & & 3081.4 & 2934.2 & \\
\hline $8(1)$ & 3067.8 & 2935.6 & & 3078.9 & 2938.1 & & 3078.0 & 2943.7 & \\
\hline $9(1)$ & 3051.8 & 2937.3 & & 3051.8 & 32937.0 & & 3051.8 & 2937.6 & \\
\hline 10(1) & 3040.9 & 2923.4 & & 3040.9 & 2923.2 & & 3040.9 & 2923.7 & \\
\hline 11(1) & 2288.4 & 2215.7 & 2215.8 & 2265.5 & 2197.3 & 2197.7 & 2266.3 & 2194.2 & 2194.7 \\
\hline 12(1) & 1810.0 & 1778.5 & & 1810.0 & 1778.2 & & 1810.0 & 1779.5 & \\
\hline 13(1) & 1672.8 & 1570.1 & & 1672.8 & 3 1577.4 & & 1672.8 & 1556.4 & \\
\hline 14(1) & 1501.3 & 1462.7 & & 1501.3 & 1465.5 & & 1501.3 & 1464.6 & \\
\hline 15(1) & 1490.2 & 1453.5 & & 1489.9 & 1459.4 & & 1489.9 & 1453.9 & \\
\hline $16(1)$ & 1469.9 & 1432.5 & & 1453.7 & 1407.6 & & 1452.9 & 1418.4 & \\
\hline 17(1) & 1419.9 & 1390.4 & & 1419.9 & 1385.2 & & 1419.9 & 1390.5 & \\
\hline 18(1) & 1376.0 & 1335.5 & & 1375.7 & 1337.5 & & 1375.7 & 1338.4 & \\
\hline 19(1) & 1369.9 & 1317.2 & & 1369.9 & 1320.4 & & 1369.9 & 1313.7 & \\
\hline 20(1) & 1316.7 & 1290.9 & & 1316.3 & 31286.0 & & 1317.1 & 1289.2 & \\
\hline 21(1) & 1288.3 & 1256.0 & & 1299.7 & 1285.8 & & 1296.9 & 1267.5 & \\
\hline $22(1)$ & 1283.0 & 1250.2 & & 1284.8 & 31287.2 & & 1285.7 & 1258.7 & \\
\hline $23(1)$ & 1279.1 & 1243.9 & & 1277.6 & 1243.3 & & 1278.4 & 1253.1 & \\
\hline 24(1) & 1262.8 & 1231.2 & & 1273.2 & 1231.6 & & 1272.8 & 1247.8 & \\
\hline 25(1) & 1223.9 & 1204.1 & & 1225.2 & 2 1207.0 & & 1224.9 & 1210.0 & \\
\hline $26(1)$ & 1148.6 & 1120.3 & & 1148.8 & 31125.5 & & 1148.8 & 1120.5 & \\
\hline $27(1)$ & 1142.9 & 1115.3 & & 1142.9 & 1138.4 & & 1142.9 & 1114.0 & \\
\hline $28(1)$ & 1112.0 & 1085.7 & & 1112.0 & 1086.5 & & 1112.0 & 1084.0 & \\
\hline $29(1)$ & 1053.0 & 1025.7 & & 1054.8 & 31029.6 & & 1055.6 & 1026.1 & \\
\hline 30(1) & 1024.7 & 999.2 & & 1024.0 & 997.3 & & 1024.6 & 994.3 & \\
\hline $31(1)$ & 998.1 & 980.1 & & 1000.6 & 989.7 & & 998.1 & 980.0 & \\
\hline $32(1)$ & 954.4 & 937.3 & & 947.8 & 916.0 & & 949.7 & 930.5 & \\
\hline 33(1) & 882.1 & 828.4 & & 880.6 & 822.9 & & 879.1 & 814.0 & \\
\hline $34(1)$ & 843.7 & 824.0 & & 824.2 & 813.3 & & 823.6 & 804.5 & \\
\hline $35(1)$ & 819.3 & 803.6 & & 803.9 & 732.2 & & 809.2 & 796.1 & \\
\hline $36(1)$ & 790.5 & 771.1 & & 789.8 & 840.7 & & 786.4 & 768.1 & \\
\hline $37(1)$ & 755.1 & 741.5 & & 754.5 & 745.0 & & 752.4 & 680.6 & \\
\hline 38(1) & 749.9 & 735.8 & & 743.0 & 712.2 & & 745.2 & 728.6 & \\
\hline $39(1)$ & 666.5 & 655.1 & & 697.2 & 690.4 & & 697.1 & 684.3 & \\
\hline 40(1) & 639.7 & 632.5 & & 639.9 & 645.1 & & 639.9 & 638.5 & \\
\hline 41(1) & 628.5 & 603.3 & & 629.0 & 606.6 & & 629.0 & 602.9 & \\
\hline $42(1)$ & 515.6 & 511.4 & & 515.4 & 505.5 & & 515.3 & 505.6 & \\
\hline $43(1)$ & 380.4 & 379.9 & & 380.4 & . 382.4 & & 380.3 & 382.3 & \\
\hline 44(1) & 333.7 & 327.1 & & 334.6 & 329.3 & & 334.6 & 317.9 & \\
\hline $45(1)$ & 292.9 & 309.3 & & 292.8 & $\quad 309.9$ & & 292.6 & 306.7 & \\
\hline 46(1) & 252.0 & 283.6 & & 251.4 & . 285.0 & & 251.5 & 261.2 & \\
\hline $47(1)$ & 230.1 & 239.1 & & 229.5 & $\quad 236.7$ & & 229.4 & 223.8 & \\
\hline 48(1) & 192.2 & 190.2 & & 194.1 & 189.7 & & 192.7 & 197.1 & \\
\hline 49(1) & 157.4 & 128.6 & & 159.4 & . 145.9 & & 160.1 & 129.8 & \\
\hline $50(1)$ & 122.9 & 122.8 & & 122.8 & 108.4 & & 123.7 & 115.1 & \\
\hline $51(1)$ & 90.4 & 92.6 & & 92.0 & 85.0 & & 90.3 & 117.8 & \\
\hline $52(1)$ & 67.2 & 82.7 & & 67.4 & -37.6 & & 68.6 & 78.6 & \\
\hline $53(1)$ & 40.7 & 57.2 & & 40.1 & 319.7 & & 40.0 & 14.6 & \\
\hline $54(1)$ & 33.8 & 37.6 & & 33.0 & -248.5 & & 33.1 & 76.1 & \\
\hline Frequ & encies -- & 2288.4 & & & 2265.5 & & & 2266.3 & \\
\hline Red. $n$ & asses -- & 2.2502 & & & 2.2484 & & & 2.2482 & \\
\hline Frc & onsts -- & 6.9428 & & & 6.7988 & & & 6.8034 & \\
\hline & nten -- & 6.4381 & & & 13.339 & & & 13.609 & \\
\hline & rel. Int. & 0.47 & & & 0.98 & & & 1.00 & \\
\hline
\end{tabular}

Harmonic \& Anharmonic v's of Met- $d_{1}$, gauche A methyl: B3LYP/6-31+G(d,p) Harm = harmonic, Anh = anharmonic, Anh-FR $=$ anharmonic $v$ with Fermi resonance removed.

\begin{tabular}{|c|c|c|c|c|c|c|c|c|c|}
\hline & anti C-D & & & gauche & $C-D$ & & gauche & C-D & \\
\hline & Harm & Anh & Anh-FR & Harm & Anh & Anh-FR & Harm & Anh & Anh-FR \\
\hline 1(1) & 3736.9 & 3532.7 & & 3736.9 & 3532.6 & & 3736.9 & 3532.6 & \\
\hline $2(1)$ & 3585.8 & 3414.1 & & 3585.8 & 3414.1 & & 3585.8 & 3413.9 & \\
\hline $3(1)$ & 3499.9 & 3347.7 & & 3499.9 & 3349.3 & & 3499.9 & 3349.1 & \\
\hline 4(1) & 3130.2 & 2967.9 & & 3144.2 & 2989.7 & & 3141.6 & 2987.8 & \\
\hline $5(1)$ & 3121.2 & 2961.2 & & 3121.5 & 2962.4 & & 3121.5 & 2963.3 & \\
\hline $6(1)$ & 3101.9 & 2944.7 & & 3101.9 & 2944.3 & & 3101.9 & 2944.0 & \\
\hline $7(1)$ & 3078.5 & 2931.5 & & 3087.9 & 2951.3 & & 3078.7 & 2936.9 & \\
\hline $8(1)$ & 3072.1 & 2934.6 & & 3078.5 & 2930.8 & & 3078.5 & 2931.3 & \\
\hline 9(1) & 3057.7 & 2930.8 & & 3057.7 & 2931.0 & & 3057.7 & 2931.3 & \\
\hline 10(1) & 3048.6 & 2918.9 & & 3048.7 & 2918.7 & & 3048.6 & 2918.4 & \\
\hline 11(1) & 2288.0 & 2214.4 & 2215.3 & 2265.6 & 2190.5 & 2191.0 & 2274.4 & 2198.1 & 2198.5 \\
\hline 12(1) & 1810.3 & 1779.2 & & 1810.3 & 1780.5 & & 1810.3 & 1780.6 & \\
\hline 13(1) & 1672.8 & 1562.9 & & 1672.8 & 1573.5 & & 1672.8 & 1573.0 & \\
\hline 14(1) & 1498.5 & 1456.2 & & 1498.3 & 1456.4 & & 1498.2 & 1460.3 & \\
\hline 15(1) & 1471.2 & 1440.4 & & 1471.2 & 1431.6 & & 1471.8 & 31437.0 & \\
\hline 16(1) & 1470.2 & 1429.5 & & 1459.8 & 1407.0 & & 1449.9 & 1412.1 & \\
\hline 17(1) & 1419.9 & 1383.7 & & 1419.6 & 1378.5 & & 1419.8 & 1383.7 & \\
\hline 18(1) & 1369.7 & 1333.7 & & 1369.4 & 1339.4 & & 1369.4 & 1336.1 & \\
\hline 19(1) & 1366.3 & 1327.7 & & 1366.3 & 1315.7 & & 1366.3 & 1324.0 & \\
\hline 20(1) & 1322.1 & 1281.4 & & 1322.2 & 1280.9 & & 1322.3 & 1284.7 & \\
\hline 21(1) & 1293.2 & 1257.3 & & 1297.4 & 1265.3 & & 1300.6 & 1268.0 & \\
\hline 22(1) & 1286.2 & 1236.4 & & 1290.1 & 1256.3 & & 1292.3 & 1259.6 & \\
\hline $23(1)$ & 1279.5 & 1239.2 & & 1284.4 & 1247.0 & & 1285.4 & 1252.6 & \\
\hline 24(1) & 1264.5 & 1231.6 & & 1267.4 & 1237.8 & & 1268.3 & 1236.6 & \\
\hline $25(1)$ & 1225.9 & 1186.8 & & 1225.0 & 1187.5 & & 1224.2 & 1188.7 & \\
\hline 26(1) & 1154.6 & 1124.4 & & 1154.8 & 1124.9 & & 1154.9 & 1127.9 & \\
\hline $27(1)$ & 1145.2 & 1020.4 & & 1145.2 & 1107.1 & & 1145.3 & 31107.0 & \\
\hline $28(1)$ & 1116.9 & 1079.1 & & 1117.1 & 1084.4 & & 1117.3 & 1084.0 & \\
\hline $29(1)$ & 1051.5 & 1019.2 & & 1054.3 & 1023.0 & & 1054.6 & 1024.3 & \\
\hline 30(1) & 1024.7 & 998.6 & & 1028.5 & 1001.0 & & 1029.1 & 1004.2 & \\
\hline $31(1)$ & 989.9 & 959.8 & & 989.9 & 960.0 & & 990.8 & 3961.3 & \\
\hline 32(1) & 953.4 & . 932.7 & & 947.5 & 919.4 & & 939.5 & 923.1 & \\
\hline $33(1)$ & 889.2 & 828.3 & & 883.5 & 820.6 & & 883.6 & 820.9 & \\
\hline 34(1) & 843.3 & 817.4 & & 816.4 & 793.6 & & 816.2 & 792.0 & \\
\hline $35(1)$ & 796.0 & 772.0 & & 796.0 & 776.9 & & 796.2 & 774.5 & \\
\hline $36(1)$ & 786.6 & 767.3 & & 782.1 & 766.6 & & 786.2 & 768.7 & \\
\hline $37(1)$ & 747.9 & 721.7 & & 743.2 & 727.2 & & 743.7 & 726.4 & \\
\hline $38(1)$ & 729.7 & 712.4 & & 736.5 & 724.3 & & 736.0 & 735.9 & \\
\hline 39(1) & 660.7 & 644.4 & & 678.9 & 665.2 & & 678.8 & 3665.2 & \\
\hline 40(1) & 639.1 & 627.6 & & 639.5 & 628.4 & & 639.5 & 629.4 & \\
\hline 41(1) & 627.7 & 602.0 & & 628.2 & 602.1 & & 628.2 & $\quad 602.1$ & \\
\hline 42(1) & 508.8 & 498.7 & & 508.9 & 499.9 & & 508.7 & 499.8 & \\
\hline 43(1) & 371.4 & 362.0 & & 371.9 & 364.3 & & 371.3 & $3 \quad 364.8$ & \\
\hline 44(1) & 345.0 & 320.0 & & 346.3 & 335.5 & & 346.0 & 333.8 & \\
\hline $45(1)$ & 291.3 & 284.2 & & 291.2 & 286.0 & & 291.5 & 286.6 & \\
\hline $46(1)$ & 278.2 & 261.8 & & 279.0 & 256.4 & & 277.5 & $5 \quad 262.3$ & \\
\hline $47(1)$ & 246.6 & 205.9 & & 246.5 & 205.6 & & 246.7 & 205.6 & \\
\hline 48(1) & 198.0 & 186.5 & & 196.7 & 185.4 & & 201.8 & $3 \quad 178.7$ & \\
\hline 49(1) & 153.5 & 127.3 & & 157.0 & 111.8 & & 153.6 & 131.8 & \\
\hline $50(1)$ & 134.7 & 73.5 & & 141.0 & 97.6 & & 135.4 & 79.3 & \\
\hline $51(1)$ & 103.5 & 58.2 & & 99.4 & 71.7 & & 103.3 & 73.3 & \\
\hline $52(1)$ & 72.8 & 56.8 & & 72.3 & 59.3 & & 73.0 & 61.2 & \\
\hline $53(1)$ & 37.5 & 28.5 & & 37.4 & 31.3 & & 37.3 & 37.5 & \\
\hline $54(1)$ & 28.7 & 20.5 & & 28.3 & 23.6 & & 28.3 & 14.4 & \\
\hline Frequ & encies -- & 2288.0 & & & 2265.6 & & & 2274.4 & \\
\hline Red. $n$ & lasses -- & 2.2511 & & & 2.2483 & & & 2.2481 & \\
\hline Frc & onsts -- & 6.9429 & & & 6.7992 & & & 6.8515 & \\
\hline & nten -- & 5.7603 & & & 12.258 & & & 9.7397 & \\
\hline & rel. Int. & 0.42 & & & 0.90 & & & 0.72 & \\
\hline
\end{tabular}




\title{
Efforts Toward Developing Direct Probes of Protein Dynamics
}

\author{
Matthew E. Cremeens, ${ }^{\dagger}$ Hiroshi Fujisaki, ${ }^{\ddagger}$ Yong Zhang, ${ }^{\ddagger}$ Jörg Zimmermann, ${ }^{\dagger}$ Laura B. Sagle ${ }^{\dagger}$ \\ Shigeo Matsuda, ${ }^{\dagger}$ Philip E. Dawson, ${ }^{\dagger}$ John E. Straub, ${ }^{\ddagger}$ and Floyd E. Romesberg ${ }^{\dagger *}$ \\ ${ }^{\dagger}$ Department of Chemistry, The Scripps Research Institute, 10550 North Torrey Pines Road, La Jolla, CA \\ 92037 and Department of Chemistry, Boston University, 590 Commonwealth Avenue, Boston, MA 02215
}

Harmonic \& Anharmonic v's of Met- $d_{1}$, gauche B methyl: B3LYP/6-31+G(d,p) Harm = harmonic, Anh = anharmonic, Anh-FR $=$ anharmonic $v$ with Fermi resonance removed.

\begin{tabular}{|c|c|c|c|c|c|c|c|c|c|}
\hline & anti $C-[$ & & & gauche & C-D & & gauche & e C-D & \\
\hline & Harm & Anh & Anh-FR & २ Harm & Anh & Anh-FR & २ Harm & Anh & Anh-FR \\
\hline 1(1) & 3734.6 & 3540.5 & & 3734.6 & 3540.6 & & 3734.6 & 3540.3 & \\
\hline 2(1) & 3588.6 & 3415.0 & & 3588.6 & 3414.6 & & 3588.6 & 3415.6 & \\
\hline $3(1)$ & 3499.7 & 3346.3 & & 3499.7 & 3347.1 & & 3499.7 & 7 3347.1 & \\
\hline $4(1)$ & 3132.7 & 2969.4 & & 3142.2 & 2986.7 & & 3145.6 & 2985.0 & \\
\hline $5(1)$ & 3119.9 & 2966.0 & & 3120.2 & 2966.7 & & 3120.2 & 2966.3 & \\
\hline $6(1)$ & 3097.7 & 2943.4 & & 3097.7 & 2943.8 & & 3097.7 & 72943.5 & \\
\hline $7(1)$ & 3084.3 & 2944.5 & & 3084.3 & 2962.8 & & 3090.3 & 32948.0 & \\
\hline $8(1)$ & 3074.7 & 2936.3 & & 3079.7 & 2941.0 & & 3084.3 & 32935.6 & \\
\hline $9(1)$ & 3054.3 & 2929.8 & & 3054.4 & 2930.5 & & 3054.4 & 2929.4 & \\
\hline $10(1)$ & 3049.2 & 2926.7 & & 3049.2 & 2926.4 & & 3049.2 & 2926.5 & \\
\hline 11(1) & 2288.1 & 2212.7 & 2213.3 & 32276.8 & 2194.5 & 52194.8 & 3 2266.7 & 2192.6 & 2193.0 \\
\hline 12(1) & 1807.5 & 1778.8 & & 1807.5 & 1778.8 & & 1807.5 & 51773.7 & \\
\hline $13(1)$ & 1670.3 & 1529.7 & & 1670.3 & 1552.3 & & 1670.3 & 31556.1 & \\
\hline 14(1) & 1495.3 & 1461.0 & & 1495.0 & 1461.6 & & 1495.1 & 1460.5 & \\
\hline $15(1)$ & 1470.8 & 1428.4 & & 1471.3 & 1429.6 & & 1470.8 & 31429.9 & \\
\hline $16(1)$ & 1469.4 & 1430.1 & & 1449.4 & 1405.9 & & 1460.0 & 1420.8 & \\
\hline $17(1)$ & 1418.6 & 1379.5 & & 1418.6 & 1378.6 & & 1418.6 & 1380.7 & \\
\hline $18(1)$ & 1373.8 & 1328.2 & & 1373.4 & 1325.8 & & 1373.1 & 1327.6 & \\
\hline 19(1) & 1368.0 & 1330.6 & & 1368.0 & 1330.3 & & 1368.1 & 1332.9 & \\
\hline $20(1)$ & 1323.0 & 1289.3 & & 1322.7 & 1289.8 & & 1321.7 & 71289.2 & \\
\hline $21(1)$ & 1291.2 & 1265.4 & & 1300.7 & 1275.2 & & 1294.3 & 31263.5 & \\
\hline $22(1)$ & 1282.9 & 1247.0 & & 1291.6 & 1262.4 & & 1292.3 & 31268.6 & \\
\hline $23(1)$ & 1279.1 & 1242.0 & & 1283.2 & 1237.8 & & 1282.4 & 1240.3 & \\
\hline $24(1)$ & 1266.6 & 1235.5 & & 1267.7 & 1240.2 & & 1266.0 & 1237.3 & \\
\hline $25(1)$ & 1224.1 & 1199.0 & & 1224.0 & 1197.3 & & 1224.2 & 2 1199.2 & \\
\hline $26(1)$ & 1155.2 & 1132.2 & & 1155.2 & 1130.3 & & 1155.2 & 2 1131.4 & \\
\hline $27(1)$ & 1145.3 & 1108.0 & & 1145.3 & 1107.7 & & 1145.3 & 31108.5 & \\
\hline $28(1)$ & 1113.4 & 1081.1 & & 1114.0 & 1085.3 & & 1113.9 & $\begin{array}{l}9 \\
\end{array}$ & \\
\hline $29(1)$ & 1044.9 & 1018.6 & & 1046.1 & 1018.6 & & 1045.5 & 51019.8 & \\
\hline $30(1)$ & 1026.9 & 1002.8 & & 1031.5 & 1009.0 & & 1030.0 & ) 1009.4 & \\
\hline $31(1)$ & 998.3 & 980.5 & & 1001.7 & 978.5 & & 1002.2 & 983.7 & \\
\hline $32(1)$ & 953.3 & 934.9 & & 936.5 & 5921.1 & & 943.3 & 923.7 & \\
\hline $33(1)$ & 877.6 & 820.4 & & 874.9 & 816.1 & & 876.1 & 817.2 & \\
\hline $34(1)$ & 841.1 & 823.1 & & 811.4 & 792.5 & & 815.1 & 797.4 & \\
\hline $35(1)$ & 803.8 & 782.6 & & 800.8 & 3780.0 & & 795.5 & 778.3 & \\
\hline $36(1)$ & 784.8 & 770.5 & & 788.6 & 773.6 & & 787.1 & 775.9 & \\
\hline $37(1)$ & 746.5 & 730.9 & & 744.3 & 327.5 & & 744.3 & 727.3 & \\
\hline $38(1)$ & 735.2 & 727.3 & & 739.3 & 3731.3 & & 739.1 & 732.3 & \\
\hline $39(1)$ & 661.4 & 650.0 & & 679.3 & 666.4 & & 679.5 & 665.5 & \\
\hline $40(1)$ & 641.1 & 630.2 & & 641.6 & 628.6 & & 641.6 & 630.3 & \\
\hline $41(1)$ & 631.1 & 623.2 & & 631.6 & 622.3 & & 631.6 & 624.1 & \\
\hline $42(1)$ & 510.2 & 503.3 & & 510.1 & 502.4 & & 510.3 & 502.9 & \\
\hline $43(1)$ & 362.7 & 356.4 & & 362.7 & $\quad 355.6$ & & 362.8 & 355.3 & \\
\hline $44(1)$ & 354.2 & 349.3 & & 355.2 & 2. 348.2 & & 356.1 & 350.9 & \\
\hline $45(1)$ & 294.4 & 292.2 & & 294.2 & 289.8 & & 294.5 & $\quad 292.4$ & \\
\hline $46(1)$ & 253.8 & 255.1 & & 253.8 & $\begin{array}{ll}3 & 268.7\end{array}$ & & 254.2 & 254.5 & \\
\hline $47(1)$ & 250.6 & 264.8 & & 251.0 & $\quad 261.2$ & & 250.2 & 264.1 & \\
\hline $48(1)$ & 208.1 & 203.1 & & 209.5 & 205.6 & & 207.1 & 203.7 & \\
\hline $49(1)$ & 163.8 & 149.2 & & 165.3 & $\begin{array}{ll}3 & 147.3\end{array}$ & & 169.5 & 5 143.7 & \\
\hline $50(1)$ & 124.8 & 111.0 & & 126.1 & 75.2 & & 129.7 & 114.3 & \\
\hline $51(1)$ & 106.7 & 84.0 & & 107.0 & 84.2 & & 104.0 & 86.1 & \\
\hline $52(1)$ & 68.6 & 65.3 & & 68.8 & 61.4 & & 67.1 & 63.9 & \\
\hline $53(1)$ & 34.8 & 3.3 & & 34.9 & 6.3 & & 34.9 & 1.8 & \\
\hline $54(1)$ & 28.3 & 52.5 & & 27.4 & 47.2 & & 27.7 & 47.0 & \\
\hline Freq & ncies -- & 2288.1 & & & 2276.8 & & & 2266.7 & \\
\hline Red. & nasses -- & 2.2511 & & & 2.2475 & & & 2.2484 & \\
\hline Frc & consts -- & 6.9437 & & & 6.8647 & & & 6.8062 & \\
\hline & Inten -- & 5.7985 & & & 9.4263 & & & 10.881 & \\
\hline & rel. Int. & 0.43 & & & 0.69 & & & 0.80 & \\
\hline
\end{tabular}

Harmonic \& Anharmonic $v$ 's of Met- $d_{1} \cdot \mathrm{H}_{2} \mathrm{O}$, anti methyl: B3LYP/6-31G(d) Harm = harmonic, Anh = anharmonic, Anh-FR = anharmonic $v$ with Fermi resonance removed.

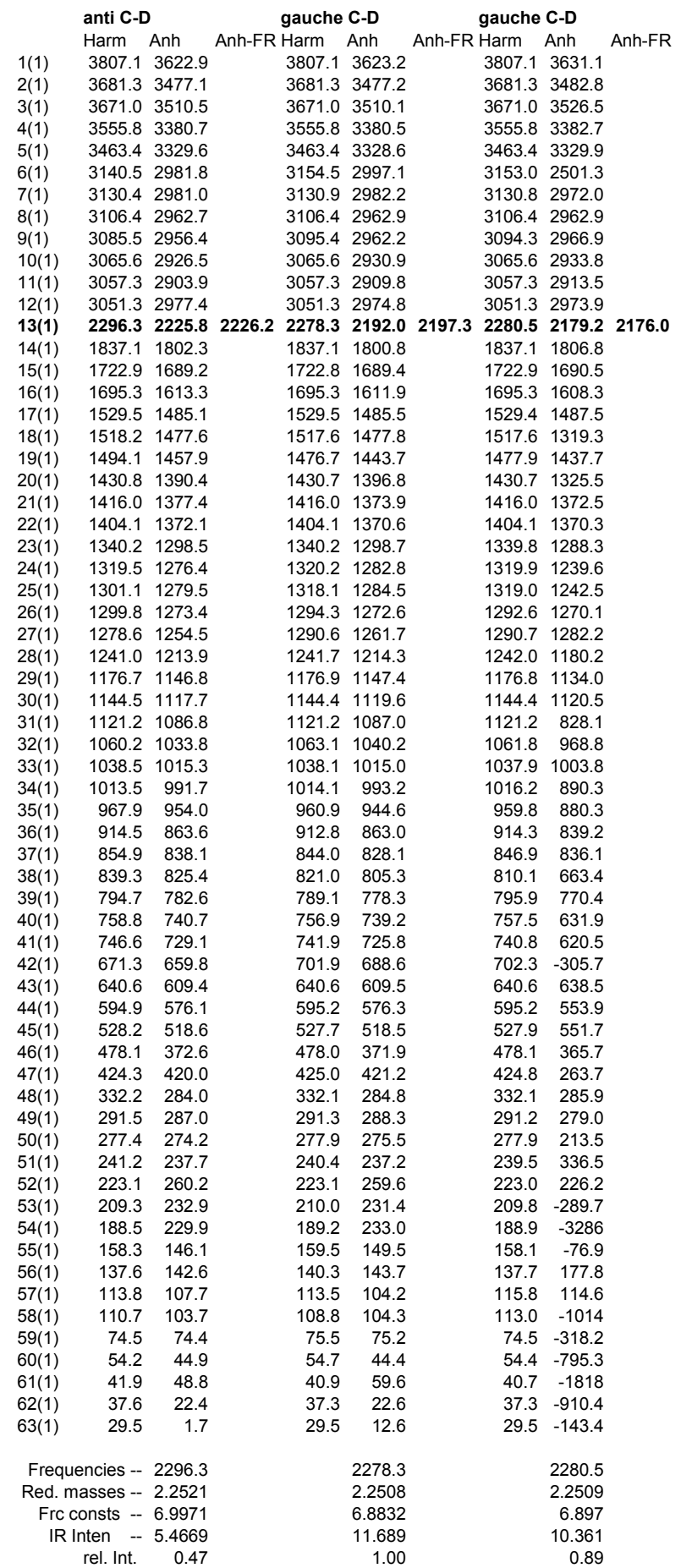




\section{Efforts Toward Developing Direct Probes of Protein Dynamics}

Matthew E. Cremeens, ${ }^{\dagger}$ Hiroshi Fujisaki, ${ }^{\ddagger}$ Yong Zhang, ${ }^{\ddagger}$ Jörg Zimmermann, ${ }^{\dagger}$ Laura B. Sagle ${ }^{\dagger}$ Shigeo Matsuda, ${ }^{\dagger}$ Philip E. Dawson, ${ }^{\dagger}$ John E. Straub,${ }^{\ddagger}$ and Floyd E. Romesberg ${ }^{\dagger *}$

${ }^{\dagger}$ Department of Chemistry, The Scripps Research Institute, 10550 North Torrey Pines Road, La Jolla, CA 92037 and Department of Chemistry, Boston University, 590 Commonwealth Avenue, Boston, MA 02215

Harmonic \& Anharmonic v's of Met- $d_{3} \cdot \mathrm{H}_{2} \mathrm{O}$, anti methyl: B3LYP/6-31G(d) Harm = harmonic, Anh = anharmonic, Anh-FR = anharmonic $v$ with Fermi resonance removed.

\begin{tabular}{|c|c|c|c|}
\hline & Harm & Anh & Anh-FR \\
\hline 1(1) & 3807.1 & 3622.3 & \\
\hline 2(1) & 3681.3 & 3477.6 & \\
\hline $3(1)$ & 3671.0 & 3507.3 & \\
\hline 4(1) & 3555.8 & 3380.6 & \\
\hline $5(1)$ & 3463.4 & 3328.6 & \\
\hline 6(1) & 3130.8 & 2982.1 & \\
\hline $7(1)$ & 3106.4 & 2962.4 & \\
\hline $8(1)$ & 3065.6 & 2928.1 & \\
\hline 9(1) & 3057.3 & 2909.0 & \\
\hline $10(1)$ & 3051.3 & 2974.4 & \\
\hline 11(1) & 2340.6 & 2256.3 & 2256.4 \\
\hline $12(1)$ & 2331.0 & 2244.0 & 2244.0 \\
\hline 13(1) & 2191.9 & 2175.8 & 2155.4 \\
\hline $14(1)$ & 1837.1 & 1803.9 & \\
\hline 15(1) & 1722.8 & 1690.1 & \\
\hline 16(1) & 1695.3 & 1611.8 & \\
\hline 17(1) & 1529.4 & 1485.3 & \\
\hline 18(1) & 1517.5 & 1478.3 & \\
\hline 19(1) & 1430.7 & 1393.8 & \\
\hline 20(1) & 1416.0 & 1370.0 & \\
\hline 21(1) & 1403.9 & 1369.2 & \\
\hline $22(1)$ & 1339.6 & 1297.0 & \\
\hline $23(1)$ & 1319.4 & 1276.5 & \\
\hline $24(1)$ & 1292.9 & 1262.1 & \\
\hline $25(1)$ & 1241.9 & 1214.9 & \\
\hline $26(1)$ & 1176.7 & 1146.8 & \\
\hline $27(1)$ & 1144.4 & 1119.0 & \\
\hline $28(1)$ & 1121.2 & 1089.0 & \\
\hline $29(1)$ & 1095.9 & 1077.6 & \\
\hline $30(1)$ & 1083.3 & 1062.9 & \\
\hline 31(1) & 1060.8 & 1040.4 & \\
\hline $32(1)$ & 1057.2 & 1037.9 & \\
\hline $33(1)$ & 1037.8 & 1014.8 & \\
\hline $34(1)$ & 1012.3 & 990.2 & \\
\hline $35(1)$ & 914.8 & 863.3 & \\
\hline $36(1)$ & 846.1 & 829.0 & \\
\hline $37(1)$ & 809.4 & 797.4 & \\
\hline 38(1) & 787.2 & 773.9 & \\
\hline $39(1)$ & 753.1 & 735.8 & \\
\hline 40(1) & 744.5 & 737.9 & \\
\hline 41(1) & 732.4 & 717.6 & \\
\hline 42(1) & 667.6 & 656.2 & \\
\hline 43(1) & 640.6 & 609.5 & \\
\hline 44(1) & 594.8 & 575.6 & \\
\hline $45(1)$ & 527.2 & 519.1 & \\
\hline $46(1)$ & 477.8 & 373.8 & \\
\hline $47(1)$ & 422.7 & 418.6 & \\
\hline $48(1)$ & 331.8 & 284.0 & \\
\hline 49(1) & 290.6 & 286.4 & \\
\hline $50(1)$ & 277.4 & 273.9 & \\
\hline 51(1) & 234.6 & 228.0 & \\
\hline $52(1)$ & 222.8 & 262.9 & \\
\hline $53(1)$ & 207.4 & 231.6 & \\
\hline $54(1)$ & 187.7 & 226.8 & \\
\hline $55(1)$ & 147.7 & 139.3 & \\
\hline $56(1)$ & 130.4 & 136.3 & \\
\hline $57(1)$ & 113.4 & 103.8 & \\
\hline 58(1) & 102.8 & 99.2 & \\
\hline $59(1)$ & 73.3 & 73.1 & \\
\hline $60(1)$ & 53.7 & 40.9 & \\
\hline 61(1) & 39.8 & 54.2 & \\
\hline $62(1)$ & 36.5 & 22.4 & \\
\hline $63(1)$ & 29.4 & 12.0 & \\
\hline cies -- & 2191.9 & 2331 & 2340.6 \\
\hline Red. masses -- & 2.1051 & 2.3879 & 2.3807 \\
\hline Frc consts -- & 5.9588 & 7.6447 & 7.6841 \\
\hline IR Inten -- & 16.09 & 5.9353 & 2.704 \\
\hline rel. Int. & 1.00 & 0.37 & 0.17 \\
\hline
\end{tabular}




\section{Efforts Toward Developing Direct Probes of Protein Dynamics}

Matthew E. Cremeens, ${ }^{\dagger}$ Hiroshi Fujisaki, ${ }^{\ddagger}$ Yong Zhang, ${ }^{\ddagger}$ Jörg Zimmermann, ${ }^{\dagger}$ Laura B. Sagle ${ }^{\dagger}$

Shigeo Matsuda, ${ }^{\dagger}$ Philip E. Dawson, ${ }^{\dagger}$ John E. Straub,${ }^{\ddagger}$ and Floyd E. Romesberg ${ }^{\dagger *}$

${ }^{\dagger}$ Department of Chemistry, The Scripps Research Institute, 10550 North Torrey Pines Road, La Jolla, CA 92037 and Department of Chemistry, Boston University, 590 Commonwealth Avenue, Boston, MA 02215

\section{Resonant modes in methionine relevant to VER based on B3LYP/6-31+G(d,p) calculations}

We show the resonant bath modes that satisfy the frequency matching condition and have large $3^{\text {rd }}$ order coupling coefficients. They are basically localized on the methyl group and $\mathrm{CH}$ or $\mathrm{CD}$ bending modes.

Met- $d_{1}-15$ case:

Mode $23\left(946.5 \mathrm{~cm}^{-1}\right)$

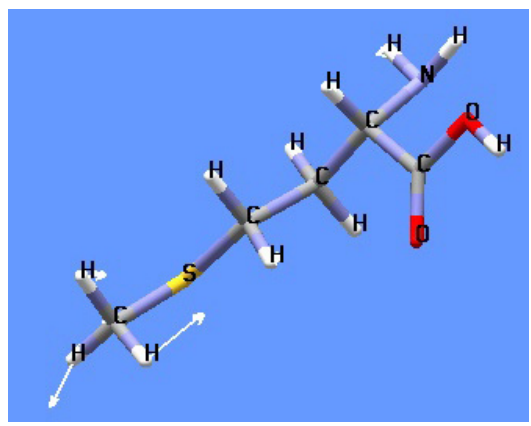

\section{Mode $33\left(1298.0 \mathrm{~cm}^{-1}\right)$}

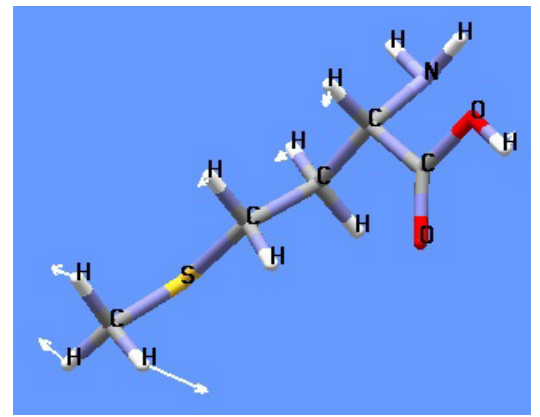

Met- $d_{3}$ case:

Mode $29\left(1078.4 \mathrm{~cm}^{-1}\right)$

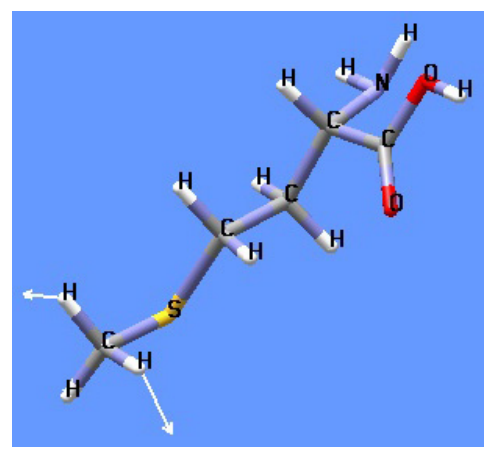

Mode $28\left(1065.0 \mathrm{~cm}^{-1}\right)$

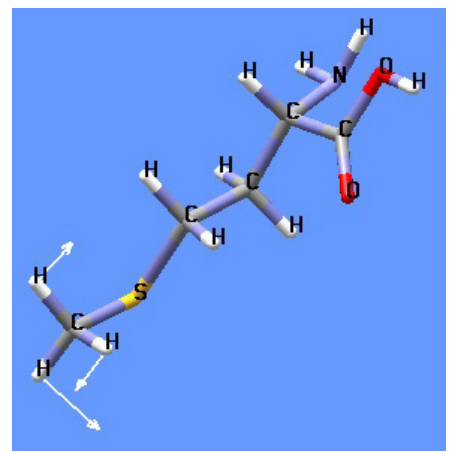

Mode $26\left(1042.4 \mathrm{~cm}^{-1}\right)$

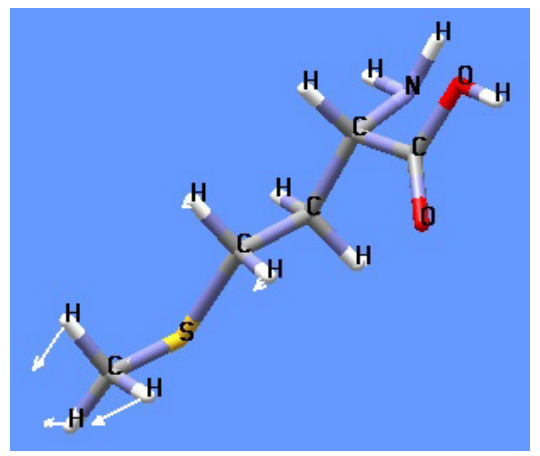

\section{Numerical analysis}

Fermi resonance parameter (different from the parameter defined by Hougen, J. T. J. Chem. Phys. 1962, 37, 403-408):

$$
\begin{gathered}
r_{k l}=\left|\frac{\left\langle 1_{S}, 0_{k}, 0_{l}|V| 0_{S}, 1_{k}, 1_{l}\right\rangle}{\hbar\left(\omega_{S}-\omega_{k}-\omega_{l}\right)}\right|=\frac{\left|C_{S k l}\right|}{\hbar\left|\omega_{S}-\omega_{k}-\omega_{l}\right|} \sqrt{\frac{\hbar}{2 \omega_{S}} \sqrt{\frac{\hbar}{2 \omega_{k}}}} \sqrt{\frac{\hbar}{2 \omega_{l}}} \\
r_{k k}=\left|\frac{\left\langle 1_{S}, 0_{k}|V| 0_{S}, 2_{k}\right\rangle}{\hbar\left(\omega_{S}-2 \omega_{k}\right)}\right|=\frac{\left|C_{S k k}\right|}{\hbar\left|\omega_{S}-2 \omega_{k}\right|} \sqrt{\frac{\hbar}{2 \omega_{S}}} \frac{\hbar}{\sqrt{2} \omega_{k}}
\end{gathered}
$$

where $C_{S k l}$ is the $3^{\text {rd }}$ order coupling constant between mode $S$ and $k$ and $l, \omega_{k}$ is the normal mode frequency, and the interaction is given by $V=C_{S k l} q_{S} q_{k} q_{l}$. From Eq. (1.1), we calculate $r_{23,33}=0.06$ for Met- $d_{1}-15$ case, which is very small. On the other hand, employing Eq. (1.2), we have $r_{29,29}=0.8, r_{28,28}=0.3, r_{26,26}=0.3$ for the symmetric stretch in Met$d_{3}$, which are moderate values. For the two asymmetric modes, this value becomes less than 0.1 . (Note that if $r>>1$, we can say that a strong Fermi resonance occurs. In this case, a single absorption line splits into two with the same amplitude.) 


\section{Efforts Toward Developing Direct Probes of Protein Dynamics}

Matthew E. Cremeens, ${ }^{\dagger}$ Hiroshi Fujisaki, ${ }^{\ddagger}$ Yong Zhang, ${ }^{\ddagger}$ Jörg Zimmermann, ${ }^{\dagger}$ Laura B. Sagle ${ }^{\dagger}$ Shigeo Matsuda, ${ }^{\dagger}$ Philip E. Dawson, ${ }^{\dagger}$ John E. Straub,${ }^{\ddagger}$ and Floyd E. Romesberg ${ }^{\dagger *}$

${ }^{\dagger}$ Department of Chemistry, The Scripps Research Institute, 10550 North Torrey Pines Road, La Jolla, CA 92037 and Department of Chemistry, Boston University, 590 Commonwealth Avenue, Boston, MA 02215

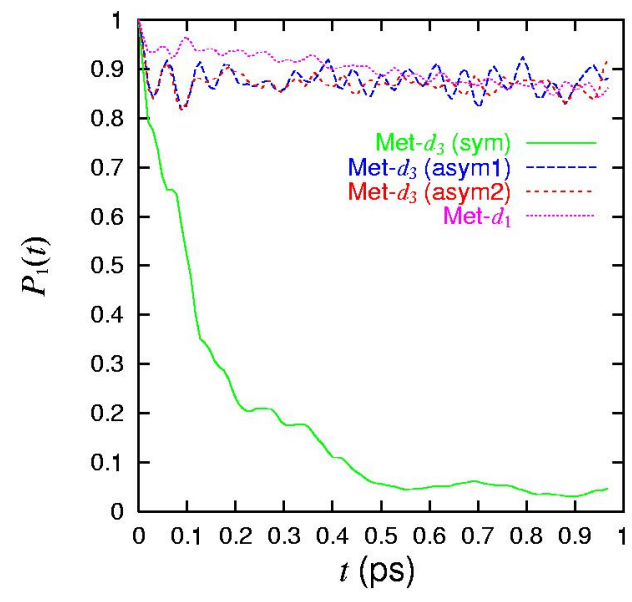

DFT result without the anharmonic correction.

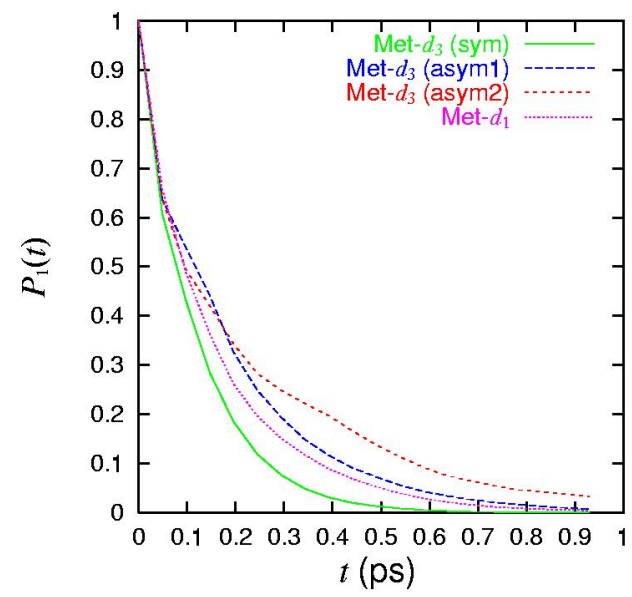

CHARMM result for Met $80-d_{3}$ in cyt $\mathrm{c}$ in water.

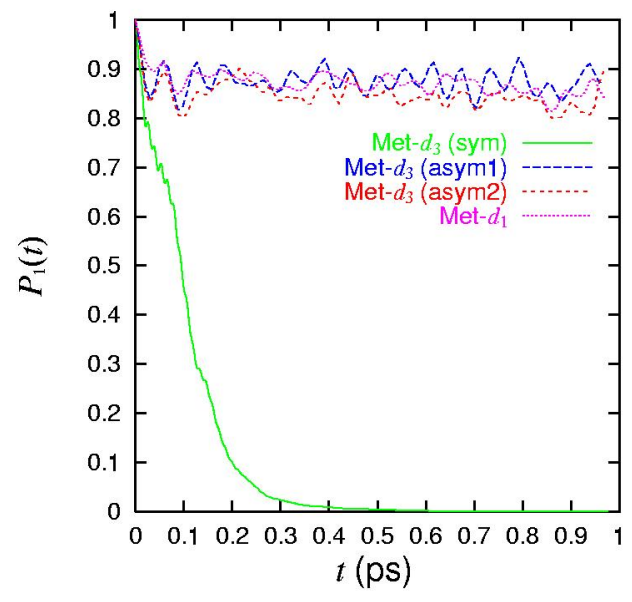

DFT result with the anharmonic correction.

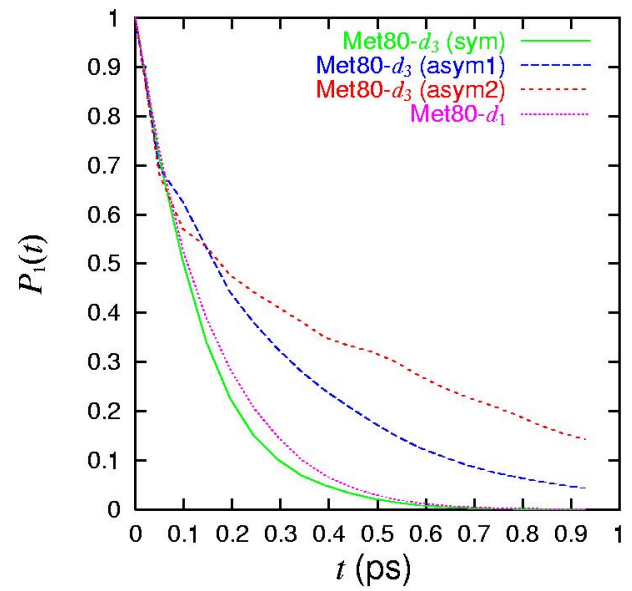

CHARMM result for Met- $d_{3}$ in water. 